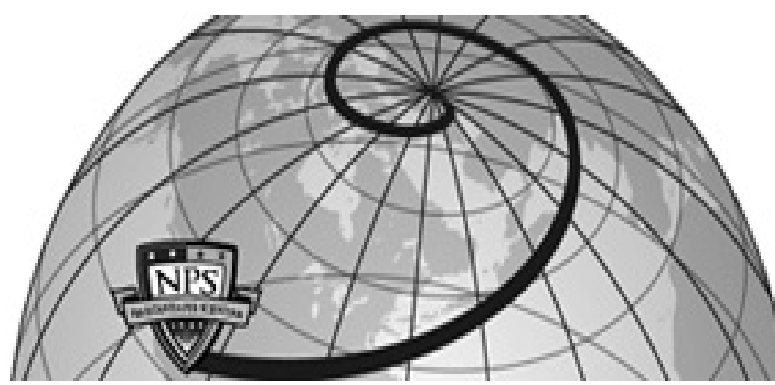

Calhoun: The NPS Institutional Archive DSpace Repository

Challenges in Mesoscale Prediction of a Nocturnal Stratocumulus-Topped Marine Boundary Layer and Implications for Operational Forecasting

Vellore, Ramesh; Wetzel, Melanie; Chai, Steven; Korain, Darko

Weather and Forecasting, Vellore et al., Vol. 22, pp.1101-1122 https://hdl.handle.net/10945/46717

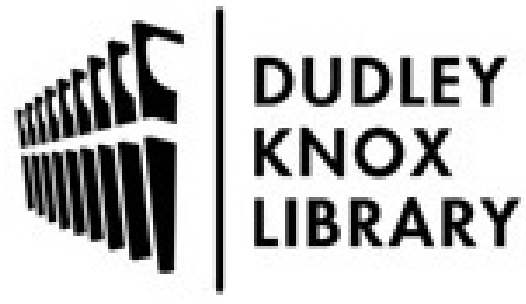

http://www.nps.edu/library
Calhoun is the Naval Postgraduate School's public access digital repository for research materials and institutional publications created by the NPS community. Calhoun is named for Professor of Mathematics Guy K. Calhoun, NPS's first appointed -- and published -- scholarly author.

Dudley Knox Library / Naval Postgraduate School 411 Dyer Road / 1 University Circle Monterey, California USA 93943 


\title{
Challenges in Mesoscale Prediction of a Nocturnal Stratocumulus-Topped Marine Boundary Layer and Implications for Operational Forecasting
}

\author{
Ramesh Vellore, Darko Koračin, Melanie Wetzel, and Steven Chai \\ Division of Atmospheric Sciences, Desert Research Institute, Reno, Nevada \\ QING WANG \\ Department of Meteorology, Naval Postgraduate School, Monterey, California
}

(Manuscript received 15 March 2006, in final form 18 December 2006)

\begin{abstract}
A numerical study using the fifth-generation Pennsylvania State University-National Center for Atmospheric Research Mesoscale Model (MM5) was performed to assess the impact of initial and boundary conditions, the parameterization of turbulence transfer and its coupling with cloud-driven radiation, and cloud microphysical processes on the accuracy of mesoscale predictions and forecasts of the cloud-capped marine boundary layer. Aircraft, buoy, and satellite data and the large eddy simulation (LES) results during the Dynamics and Chemistry of Marine Stratocumulus field experiment (DYCOMS II) in July 2001 were used in the assessment. Three of the tested input fields (Eta, NCEP, and ECMWF) show deficiencies, mainly in the thermodynamic structure of the lowest $1500 \mathrm{~m}$ of the marine atmosphere. On a positive note, the simulated marine-layer depth showed good agreement with aircraft observations using the Eta fields, while using the NCEP and ECMWF datasets underestimated the marine-layer depth by about $20 \%-30 \%$. The predicted turbulence kinetic energy (inversion strength) was about $50 \%$ of that obtained from the LES results (aircraft observed). As a consequence of moisture overprediction, the predicted liquid water path was twice the observed by $1-2 \mathrm{~g} \mathrm{~kg}^{-1}$. The sensitivity tests have shown that the selections of turbulence and cloud microphysical schemes significantly influence the turbulence estimates and cloud parameters. Two of the tested turbulence schemes (Eta PBL and Burk-Thompson) did not exhibit the coupling with radiation. The significant differences in the simulated turbulence estimates appear to be a consequence of the use of water-conserving potential temperature variables. The microphysical parameterization, which uses the number concentration of cloud drops in the autoconversion process, simulates a realistic evolution of precipitable hydrometeors in the cloudy marine layer on the positive side, but on the other hand enhances the decoupling in the turbulence structure. This study can provide guidance to operational forecasters concerning accuracy issues of the commonly used large-scale analyses for model initialization, and optimal selection of model parameterizations in order to simulate and forecast the cloudy atmospheric boundary layer over the ocean.
\end{abstract}

\section{Introduction}

For more than a decade, there has been a great demand to understand the significance of predictability in numerical weather prediction models, as the predictability issues are related to the forecast skill. Because of the complex interactions of dynamical, radiative, and microphysical processes that occur on small spatial and

Corresponding author address: Ramesh Vellore, Division of Atmospheric Sciences, Desert Research Institute, 2215 Raggio Parkway, Reno, NV 89512.

E-mail: ramesh.vellore@dri.edu

DOI: $10.1175 /$ WAF1029.1

(C) 2007 American Meteorological Society temporal scales, realistic simulation of the cloudcapped marine boundary layer remains a potential challenge for most mesoscale models and even more so for global and climate models (Driedonks and Duynkerke 1989). One of the challenging areas for operational forecasting is the southern coast of California, with its high occurrence of extensive layers of marine stratus and stratocumulus clouds and occasional fog during summertime (Leipper 1994; Nuss et al. 2000; Koračin et al. 2001; Koračin and Dorman 2001; Lewis et al. 2004; Koračin et al. 2005). Various field programs using research aircraft, buoys, ships, radar, and weather balloons have provided invaluable information to help in 
understanding the detailed structure and evolution of the cloudy marine layer along the U.S. west coast, as well as having provided data for model evaluation and improvements (Neiburger et al. 1961; Lenschow et al. 1988; Wang and Albrecht 1994; Friehe et al. 1996; Beardsley et al. 1987; Rogers et al. 1998; Stevens et al. 2003a,b). In particular, we focus on the results from a comprehensive field experiment [Dynamics and Chemistry of Marine Stratocumulus II (DYCOMS II)], which took place $500 \mathrm{~km}$ west-southwest of San Diego, California, in July 2001 (Stevens et al. 2003a,b).

The objectives of this paper are twofold: (a) to assess the accuracy of mesoscale model predictions of the structure and evolution of the stratocumulus-topped marine layer over the U.S. west coast during DYCOMS II and (b) to quantify the roles and interplay of the fundamental determinants of the marine-layer thermal energy balance. A series of sensitivity tests was conducted to examine the impacts of the choices of model physics with an emphasis on the initial and boundary conditions, turbulence, and microphysical processes, as well as other model parameters.

\section{Model setup}

The fifth-generation Penn State University-National Center for Atmospheric Research Mesoscale Model (MM5; Grell et al. 1995) has been used in a variety of studies that focused on atmospheric dynamics, cloudiness, fog, and coastal circulations along the California coast (Koračin and Dorman, 2001; Koračin et al., 2004; Koračin et al. 2005; Luria et al. 2005). For this study, the MM5 was configured in a nonhydrostatic mode with 67 vertical levels in a terrain-following vertical coordinate system. The lowest model level was set at $5 \mathrm{~m}$, and there were 49 levels below $1500 \mathrm{~m}$. Up to three domains were used with two-way interactive communication among the nests as shown in Fig. 1a. A "baseline" simulation (BL3; Table 1) was initialized for domain 1 (27$\mathrm{km}$ grid) at 0000 UTC 9 July 2001, and ran for a preforecast period of $18 \mathrm{~h}$. During this period, the wind, temperature, and moisture variables were dynamically assimilated using an analysis-nudging four-dimensional data assimilation procedure (Stauffer and Seaman 1990). The simulation for inner domains 2 (9-km grid) and 3 (3-km grid) started at 1800 UTC 9 July 2001, by interpolating the MM5 analysis from domain 1, and were run for a forecast period of $20 \mathrm{~h}$.

\section{Observations and model evaluation}

For the verification of the baseline model forecasts, we used airborne measurements, buoy observations, (a)

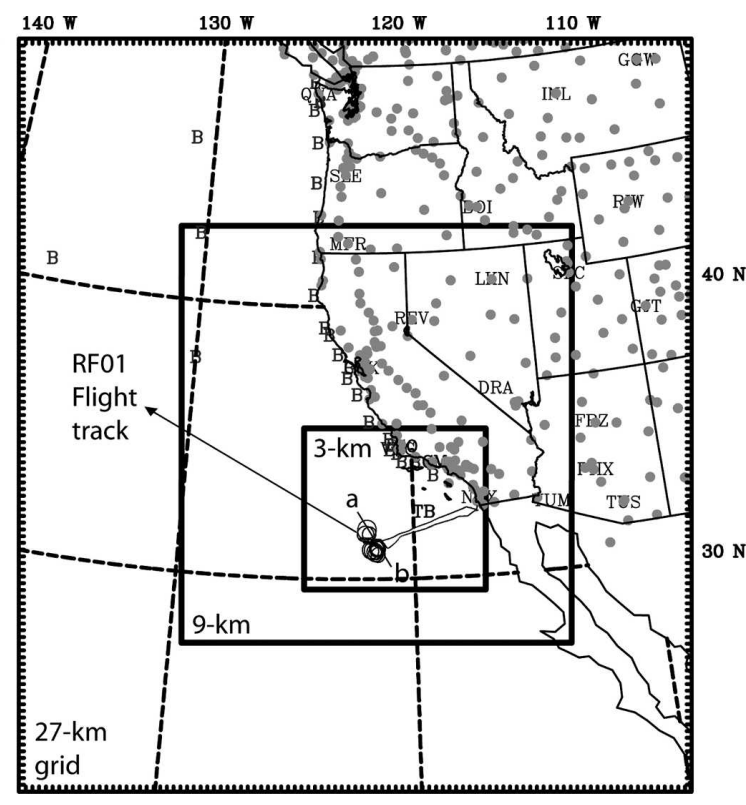

(b)
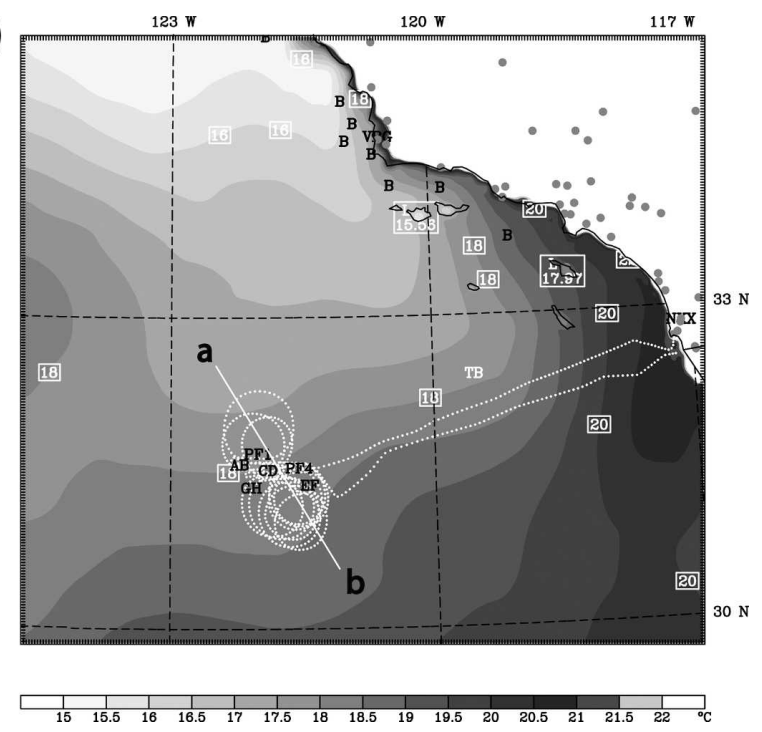

FIG. 1. (a) MM5 modeling domains (domain 1, 27-km grid; domain 2, 9-km grid; and domain 3, 3-km grid). Observational data coverage is indicated by (i) dots for surface observations, (ii) label B for buoy stations (archived by the NDBC), and (iii) upperair stations using the National Weather Service station identifiers. The aircraft track on $10 \mathrm{Jul} 2001$ (RF01) is shown inside domain 3 , and line $\mathrm{a}-\mathrm{b}$, a cross section, represents the mean displacement of the aircraft used in the analysis. (b) Same as in (a) but for a zoom-in of domain 3 and model SST on 10 Jul 2001. Indicated are the locations of flight legs $\mathrm{AB}, \mathrm{CD}, \mathrm{EF}, \mathrm{GH}$, and $\mathrm{IJ}$, as well as profiles PF1 and PF4.

and satellite-derived estimates, as well as large eddy simulation (LES) results.

\section{a. Observations}

We are using the data collected by the C-130 airborne instrumentation operated by NCAR as part of 
TABLE 1 . Summary of sensitivity experiments.

\begin{tabular}{|c|c|}
\hline Simulation & Description \\
\hline BL3 (baseline) domains & $\begin{array}{l}\text { Domain } 1(101 \times 113 \text { grid points in } x-y \text { direction; } 27-\mathrm{km} \text { grid spacing }) \text {, domain } 2(175 \times 183 \text { grid points; } \\
\text { 9-km grid spacing), and domain } 3(244 \times 217 \text { grid points; } 3 \text {-km grid spacing }) \text {; see Fig. } 1 \mathrm{a}\end{array}$ \\
\hline No. of layers & 67 unequally spaced layers (finest resolution $\sim 25 \mathrm{~m}$ in the PBL, $\sim 5 \mathrm{~m}$ near the surface) \\
\hline Nesting procedure & Two-way interactive nesting \\
\hline Model physics & $\begin{array}{l}\text { For all domains, Gayno-Seaman PBL scheme (Gayno et al. 1994), Reisner's mixed-phase microphysics } \\
\text { (Reisner et al. 1998), Kessler autoconversion process (Kessler 1969), Rapid Radiative Transfer Model } \\
\text { radiation scheme [longwave, Hu and Stamnes (1993); Mlawer et al. (1997); shortwave, Dudhia (1989)], } \\
\text { and Kain-Fritsch cumulus scheme [only in domain 1; Kain and Fritsch (1993); Kain (2004)] }\end{array}$ \\
\hline Initialization & $\begin{array}{l}\text { Eta Model output (40-km horizontal resolution, } \sim 25 \mathrm{hPa} \text { in vertical resolution; information online at } \\
\text { http://dss.ucar.edu/datasets/ds609.2), blended with surface and upper-air data (http://www.ndbc.noaa. } \\
\text { gov, http://dss.ucar.edu/datasets/ds353.4, and http://dss.ucar.edu/datasets/ds464.0) using Cressman's } \\
\text { objective analysis scheme (Cressman 1959); see Fig. 1b for SST data }\end{array}$ \\
\hline FDDA & Analysis nudging (Stauffer and Seaman 1990) \\
\hline Period of simulation & 0000 UTC 9 Jul-1400 UTC 10 Jul 2001 \\
\hline BT3, ET3 & $\begin{array}{l}\text { Same as in BL3 but for the PBL options set to the Burk-Thompson scheme (BT3) and the Eta PBL } \\
\text { scheme (ET3); these PBL schemes are based on Mellor-Yamada's turbulence closure models (Mellor } \\
\text { and Yamada 1974, 1982; Burk and Thompson 1989; Janjic 1994, 1996) }\end{array}$ \\
\hline REIS2, SCH3, N150 & $\begin{array}{l}\text { REIS2-same as in BL3 but the microphysics option is set to Reisner's scheme where the } \\
\text { autoconversion process follows the method described in Walko et al. (1995), SCH3 - same as in BL3 } \\
\text { but the microphysics option is set to Schultz's microphysics (Schultz 1995), and N150-same as in BL3 } \\
\text { but the cloud drop concentration is set to a value of } 150 \mathrm{~cm}^{-3} \text { (BL3 uses a default value of } 100 \mathrm{~cm}^{-3} \text { ) }\end{array}$ \\
\hline NCEP3 & $\begin{array}{l}\text { NCEP3—same as in BL3 but the initialization used NCEP-NCAR reanalyses (http://dss.ucar.edu/ } \\
\text { datasets/ds090.0) }\end{array}$ \\
\hline ECMWF3 & $\begin{array}{l}\text { ECMWF3—same as in BL3 but the initialization used ECMWF reanalyses (http://dss.ucar.edu/datasets/ } \\
\text { ds111.2) }\end{array}$ \\
\hline
\end{tabular}

the DYCOMS II field study (Stevens et al. 2003a,b). Figure 2 displays a time-height plot of the first research flight (RF01) on 10 July 2001, the locations of the four vertical profiles PF1-PF4, and the flight legs where the aircraft was flying at nearly constant altitude. These

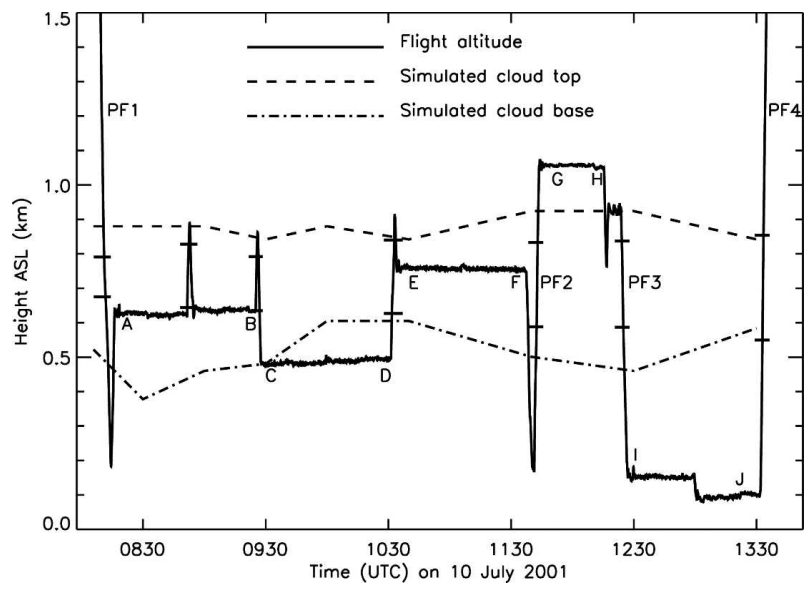

FIG. 2. RF01 flight legs and altitudes. PF1-PF4 are the profiles listed in Table 2. Flight legs $\mathrm{AB}, \mathrm{CD}, \mathrm{EF}, \mathrm{GH}$, and IJ are the cloud-base leg, subcloud leg, cloud leg, above-cloud leg, and surface flux leg, respectively. Also shown are cloud bases (dotteddashed) and cloud tops (dashed) simulated along the flight track from the baseline run, and solid markers indicated in the profile legs are the observed cloud depths during RF01. flight legs are also indicated in Fig. 1b. The observed estimates of TKE and the surface fluxes were calculated using the eddy correlation method along these flight legs. The satellite imagery during RF01 indicated significant nocturnal cloud development and enhancement of cloudiness with reference to the aircraftobserved cloud-top cooling (Fig. 3; Stevens et al. 2003a). Hourly offshore surface observations obtained from the archives of the National Data Buoy Center (NDBC; information online at http://www.ndbc. noaa.gov) are used in the verification of the predicted surface variables.

\section{b. Initialization}

The MM5 initialization using the reanalyzed Eta Model outputs at 0000 UTC 9 July 2001 for domain 1 showed warmer inversion bases $\left(\sim 13^{\circ} \mathrm{C}\right)$ and shallower marine-layer depths $(\sim 370 \mathrm{~m})$ along the cross section of the DYCOMS II RF01 flight track (line a-b) shown in Fig. 1 (see also Fig. 11). Similarly to the Eta fields, the reanalyzed European Centre for Medium-Range Weather Forecasts (ECMWF) datasets also showed a warmer marine-layer inversion base $\left(\sim 15^{\circ} \mathrm{C}\right)$ at a much shallower height of $175 \mathrm{~m}$. The reanalyzed National Centers for Environmental Prediction-National Center for Atmospheric Research (NCEP-NCAR) datasets showed inversion-base temperatures of $10^{\circ} \mathrm{C}$, but at 

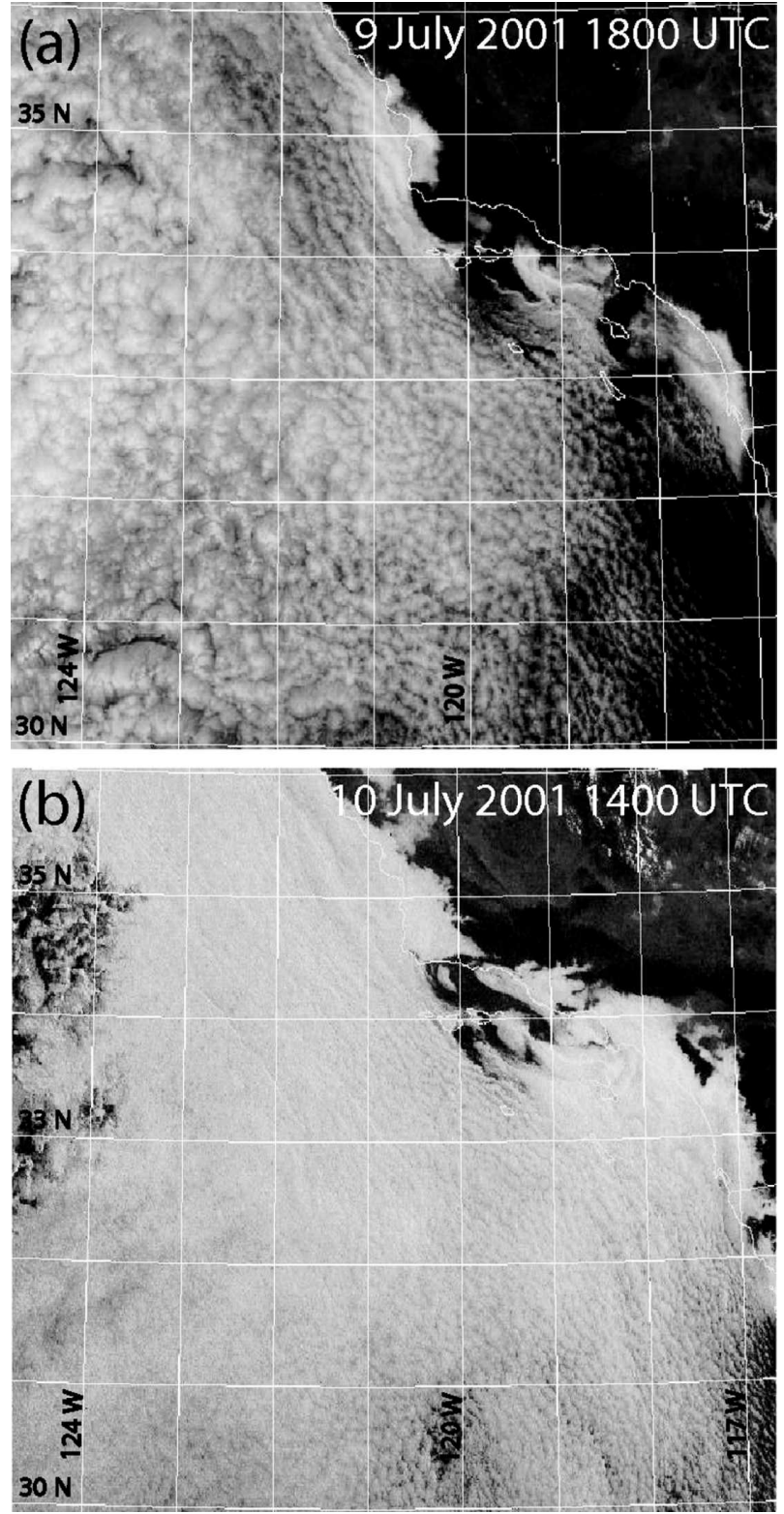

FIG. 3. Satellite visible imagery [Geostationary Operational Environmental Satellites-10 (GOES-10)] at (top) 1800 UTC 9 Jul and (bottom) 1400 UTC 10 Jul 2001 (information online at http:// www.joss.ucar.edu/dycoms/).

heights similar to the ECMWF datasets. The approximate height at which the inversion top occurred in the Eta fields (NCEP-NCAR and ECMWF) was $1000 \mathrm{~m}$ $(1500 \mathrm{~m})$. The Eta-reanalyzed mean surface water vapor mixing ratio was $11.2 \mathrm{~g} \mathrm{~kg}^{-1}$, whereas the observed value at the nearest buoy station (Tanner Banks buoy, indicated as TB in Fig. 1), located approximately 200 $\mathrm{km}$ east of the DYCOMS II target area, was $9.01 \mathrm{~g}$ $\mathrm{kg}^{-1}$; that is, the Eta fields placed more moisture in the
TABLE 2. Periods of aircraft flight profiles and sounding locations.

\begin{tabular}{cccc}
\hline \hline $\begin{array}{c}\text { Time (RF01) on } \\
\text { 10 Jul 2001 (UTC) }\end{array}$ & $\begin{array}{c}\text { Profile } \\
\text { No. }\end{array}$ & $\begin{array}{c}\text { Nearest model } \\
\text { time (UTC) }\end{array}$ & $\begin{array}{c}\text { Mean sounding } \\
\text { location }\end{array}$ \\
\hline $0805-0814$ & PF1 & 0800 & $31.68^{\circ} \mathrm{N}, 122.01^{\circ} \mathrm{W}$ \\
$1141-1144$ & PF2 & 1140 & $31.48^{\circ} \mathrm{N}, 121.61^{\circ} \mathrm{W}$ \\
$1223-1227$ & PF3 & 1230 & $31.65^{\circ} \mathrm{N}, 121.92^{\circ} \mathrm{W}$ \\
$1331-1336$ & PF4 & 1330 & $31.54^{\circ} \mathrm{N}, 121.54^{\circ} \mathrm{W}$ \\
\hline
\end{tabular}

DYCOMS II area by $25 \%$ compared with buoy observations.

\section{c. MM5 verification using aircraft and satellite data}

The forecast soundings of the baseline simulation (BL3) were extracted from the model grid point within the 3-km domain nearest the aircraft sounding locations listed in Table 2. Figure 4 shows the modeled and observed temperature and mixing ratio soundings of PF1 ( $32 \mathrm{~h}$ into the model integration) and PF4 (37.5 h into the model integration). The MM5 was able to reproduce the main structure of the marine layer as observed, and the simulated parameters in the upper part of the marine layer agree well with the aircraft measurements, especially during the later stage of the simulation (see also Fig. 2). The index of agreement [Willmott (1982); 0 being the worst agreement, and 1 being perfect agreement] between the observed and modelpredicted pairs was 0.92 for the air temperature, 0.7 for the winds, 0.8 for the total water mixing ratio, and 0.94 for the cloud water mixing ratio in the upper part of the marine layer (i.e., between $150 \mathrm{~m}$ MSL and $1 \mathrm{~km}, 35$ pairs of comparison) after $36 \mathrm{~h}$ of model simulation. However, MM5 simulated more water vapor, notably in the lower portion of the marine layer. The simulated marine layer was not as well mixed as the observed during RF01. As will be seen later, the probable cause of this is due to insufficient turbulence simulated by MM5 as compared to the LES results during RF01. Because of limitations in the vertical resolution and the inaccuracy of the input synoptic conditions and subsidence as seen in section $3 b$, the predicted inversion strength is approximately one-half of the observed $(\sim 10 \mathrm{~K})$.

Table 3 shows the statistics of the aircraft-observed and MM5-simulated variables for the stratocumulustopped marine boundary layer. There is a noticeable bias of $1.5 \mathrm{~K}$ between the aircraft-detected sea surface temperature (SST; Stevens et al. 2003b) and the SST as a lower-boundary condition in the model. The cloudtop temperature (CTT) is well reproduced by the model; that is, the differences are generally less than a 

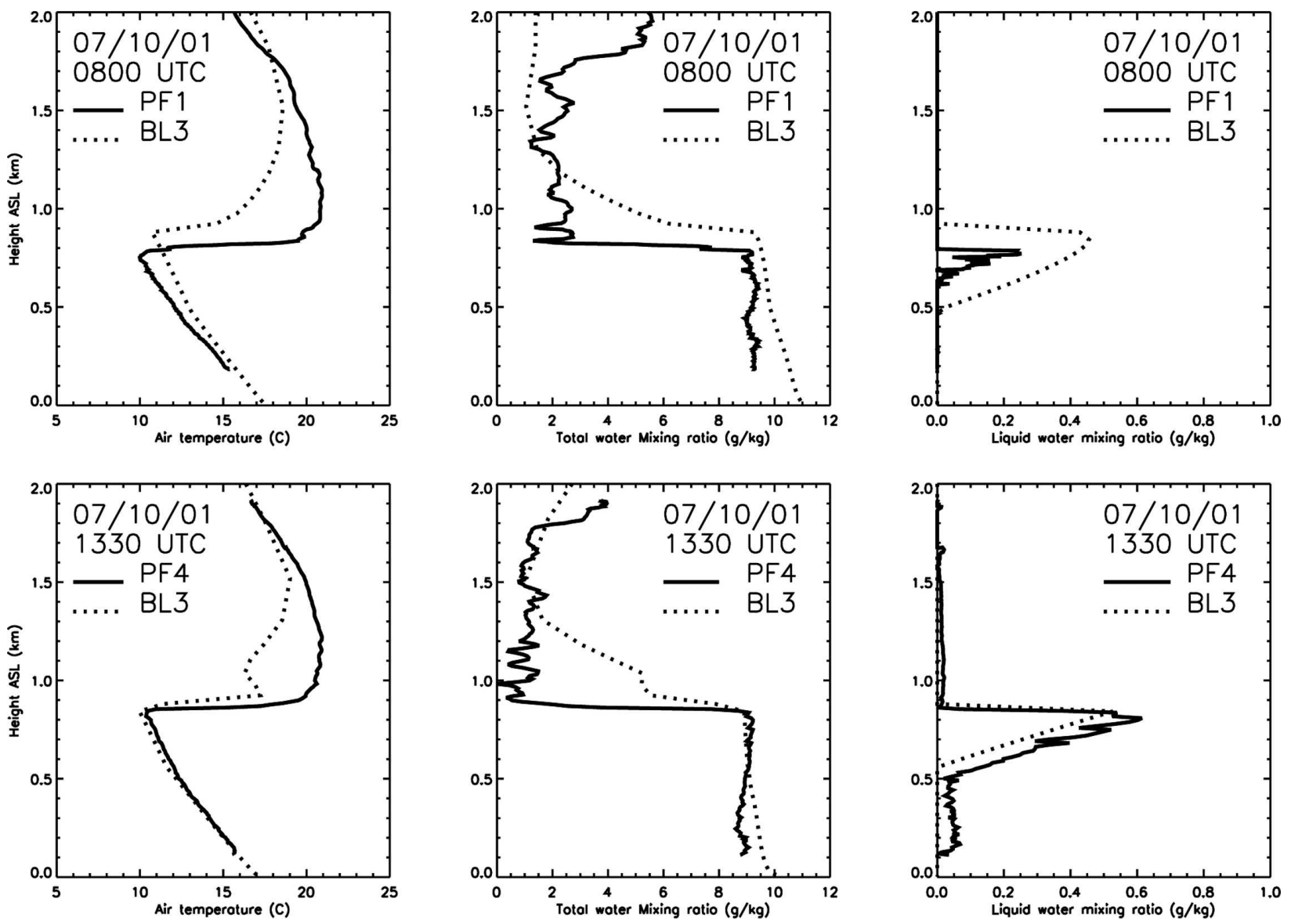

FIG. 4. Simulated baseline MM5 simulations (dashed) and aircraft-measured (solid line) temperature $\left({ }^{\circ} \mathrm{C}\right)$, vapor mixing ratio $\left(\mathrm{g} \mathrm{kg}^{-1}\right.$ ), and cloud water mixing ratio $\left(\mathrm{g} \mathrm{kg}^{-1}\right.$ ) profiles for PF1 and PF4 at (top) 0800 UTC and (bottom) 1330 UTC $10 \mathrm{Jul} 2001$.

degree. Consequently, the model's radiative heating rates agree well with the aircraft measurements. The nocturnal cloud and planetary boundary layer (PBL) depths predicted by MM5 were greater than those observed for PF1-PF3 during RF01 (see also Fig. 4). The overestimation of the simulated cloud depths was about $65 \%$, but the marine-layer depths were simulated within $10 \%$.

The simulated maximum liquid water mixing ratios [liquid water path (LWP)] for PF1-PF4 were generally

TABLE 3. Observed parameters from RF01 profiles with model-derived values shown in parentheses. Satellite-estimated values are also included for PF3. The final row shows values of variables for RF01 as reported by Stevens et al. (2003a,b). The satellite data used in the verification were obtained from the Tropical Rainfall Measuring Mission (TRMM) Microwave Imager (information online at http://trmm.gsfc.nasa.gov) and from a multichannel classification of GOES visible and infrared cloudy pixels (Wetzel et al. 2001).

\begin{tabular}{lccccrr}
\hline \hline \multicolumn{1}{c}{ Profile No. } & SST $\left({ }^{\circ} \mathrm{C}\right)$ & $\mathrm{CTT}\left({ }^{\circ} \mathrm{C}\right)$ & Cloud depth $(\mathrm{m})$ & PBL depth $(\mathrm{m})$ & Cloud-top $F_{R}\left({ }^{\circ} \mathrm{C} \mathrm{h}{ }^{-1}\right)$ & $\mathrm{LWP}(\mathrm{mm})$ \\
\hline PF1 (BL3) & $19.5(17.8)$ & $10.0(10.7)$ & $116(358)$ & $791(880)$ & $(-6.0)$ & $0.02(0.14)$ \\
PF2 (BL3) & $20.0(18.2)$ & $10.4(10.4)$ & $245(423)$ & $833(924)$ & $-7.1(-6.9)$ & $0.07(0.17)$ \\
PF3 (BL3) & $19.2(17.9)$ & $10.6(10.1)$ & $250(464)$ & $837(924)$ & $-8.4(-5.7)$ & $0.10(0.19)$ \\
Satellite & 18.1 & 9.0 & - & $900^{*}$ & - & 0.08 \\
PF4 (BL3) & $19.3(18.2)$ & $10.3(10.0)$ & $304(258)$ & $854(842)$ & $-7.5(-7.9)$ & $0.14(0.09)$ \\
Mean (BL3) & $19.5(18.0)$ & $10.3(10.3)$ & $229(375)$ & $828(892)$ & $-7.7(-6.6)$ & $0.08(0.14)$ \\
Stevens et al. (2003a,b) & 19.0 & - & 265 & 850 & - & 0.08 \\
\hline
\end{tabular}

* Value derived from an indirect evaluation of the inversion base height, which is the ratio of the difference between the satellitederived CTT and surface air temperature to adiabatic lapse rate (Koračin et al. 2003). 
TABLE 4. RMSEs (Wilks 1995) between the modeled and observed surface variables. Index of agreement [Willmott (1982): 1, perfect agreement; 0 , the worst) is computed using the cumulative modeled and observed pairs in the marine layer (56 comparison pairs, except for water vapor mixing ratio, which used 32 pairs).

\begin{tabular}{lcccc}
\hline \hline \multicolumn{1}{c}{ Variables } & Buoy $4605927 \mathrm{~km}$ & Buoy $4600627 \mathrm{~km}$ & Buoy $460473 \mathrm{~km}$ & Index of agreement \\
\hline Air temperature $\left({ }^{\circ} \mathrm{C}\right)$ & 0.5 & 0.6 & 0.5 & 0.70 \\
Sea level pressure $(\mathrm{hPa})$ & 0.9 & 0.6 & 1.2 & 0.87 \\
$u$ wind $\left(\mathrm{m} \mathrm{s}^{-1}\right)$ & 1.0 & 1.6 & 1.7 & 0.93 \\
$v$ wind $\left(\mathrm{m} \mathrm{s}^{-1}\right)$ & 1.2 & 2.2 & 0.1 & 0.67 \\
SST $\left({ }^{\circ} \mathrm{C}\right)$ & 0.5 & 0.3 & 1.7 & 0.81 \\
Water vapor mixing ratio $\left(\mathrm{g} \mathrm{kg}^{-1}\right)$ & - & - & 0.23 \\
\hline
\end{tabular}

greater, in the range of $0.45-0.83 \mathrm{~g} \mathrm{~kg}^{-1}(0.09-0.19$ $\mathrm{mm})$, while the observed range was $0.25-0.61 \mathrm{~g} \mathrm{~kg}^{-1}$ $(0.02-0.14 \mathrm{~mm})$. The statistical mean calculated for the simulated and observed profiles PF1-PF4 between 150 $\mathrm{m}$ MSL and the cloud top showed that the simulated wind speeds and wind directions of the individual profiles were in agreement with the observed mean values of $8 \mathrm{~m} \mathrm{~s}^{-1}$ and $324^{\circ}$, respectively, reported for RF01 (Stevens et al. 2003b). Although the simulated and observed mean horizontal wind fields in the marine layer were not entirely uniform with height, the relative differences or biases (i.e., the average of the difference between the simulated and observed values normalized by the observed values given as a percent) for the wind speeds and wind directions in the marine layer were generally within $15 \%$ and $6 \%$, respectively. Thus, the model results can be used for the trajectory analysis shown in section 3e, assuming that the simulated columns of marine-layer air mass move with near-uniform velocity.

\section{d. MM5 verification using surface observations}

The MM5 results were verified using the Tanner Bank buoy (NDBC buoy ID: $46047 ; 32.43^{\circ} \mathrm{N}, 119.53^{\circ} \mathrm{W}$; $224 \mathrm{~km}$ west of San Diego, California) data on the model domain with $3-\mathrm{km}$ resolution. Because of their locations with respect to the model grids, the $27-\mathrm{km}$ domain results were used to verify the data from buoys $46059\left(40.80^{\circ} \mathrm{N}, 137.48^{\circ} \mathrm{W} ; 1100 \mathrm{~km}\right.$ west of Eureka, California) and $46006\left(37.98^{\circ} \mathrm{N}, 130.00^{\circ} \mathrm{W} ; 660 \mathrm{~km}\right.$ west of San Francisco, California). The MM5 predictions of all parameters are generally in accordance with the buoy data, except for the overprediction of the vapor mixing ratio. Notice that the model's SST differs by only a degree or less compared with the buoy data. As there are fewer observed and simulated time series samples for verification, overall statistical measures such as the root-mean-square error (RMSE; Wilks 1995) and index of agreement are selected to evaluate the model performance and are shown in Table 4. It can be seen from the Tanner Bank buoy data that the MM5 overestimated the mixing ratio by $1 \mathrm{~g} \mathrm{~kg}^{-1}$. The index of agreement showed good agreement, with indices for the surface variables in the range of $0.7-0.9$, except for the water vapor mixing ratios, which had an index of agreement of 0.23 . Although the Tanner Bank buoy surface observations were assimilated into the model initialization, because of prevailing overestimations of moisture in the surroundings, the water vapor mixing ratios quickly adjusted to the surroundings within the first $6-12 \mathrm{~h}$ of the model simulation. SST was consistently overestimated, on average by $0.5^{\circ}-1.0^{\circ} \mathrm{C}$ at other buoy station locations (not shown here) that were very close to the California coast. The SST discrepancy decreases with increased distance from the coastline.

\section{e. MM5 verification in Eulerian and quasi-Lagrangian frameworks}

Flight legs AB, CD, and EF, shown in Figs. 1 and 2, were considered for verification within an Eulerian frame of reference. Flight leg $\mathrm{AB}(\mathrm{CD}, \mathrm{EF})$ was located on the cold (warm) side of the SSTs along the RF01 flight track shown in Fig. 1b. Figures 5a,b show time series of the model-predicted air temperature and total water mixing ratio collocated with aircraft measurements along the flight legs. The model was able to follow slightly different temperature regimes along the tracks, and the moisture amounts differ by about $1 \mathrm{~g}$ $\mathrm{kg}^{-1}$ or less compared with the aircraft measurements. The predicted distribution of the thermodynamic variables was generally consistent with the observations, with the exception that MM5 predicted higher temperatures and significant cloud water variability along flight leg $\mathrm{AB}$, which affects the thermal stability causing large fluctuations in the air temperature. Figure $5 \mathrm{c}$ shows the simulated and observed turbulence kinetic energy (TKE) along these flight legs (one TKE value for each leg), and it can be seen that the simulated TKE estimates were approximately one-half of the observed magnitudes. As will be seen later, as a consequence of this, the simulated marine boundary layer was not as well mixed as that simulated by the LES (Stevens et al. 

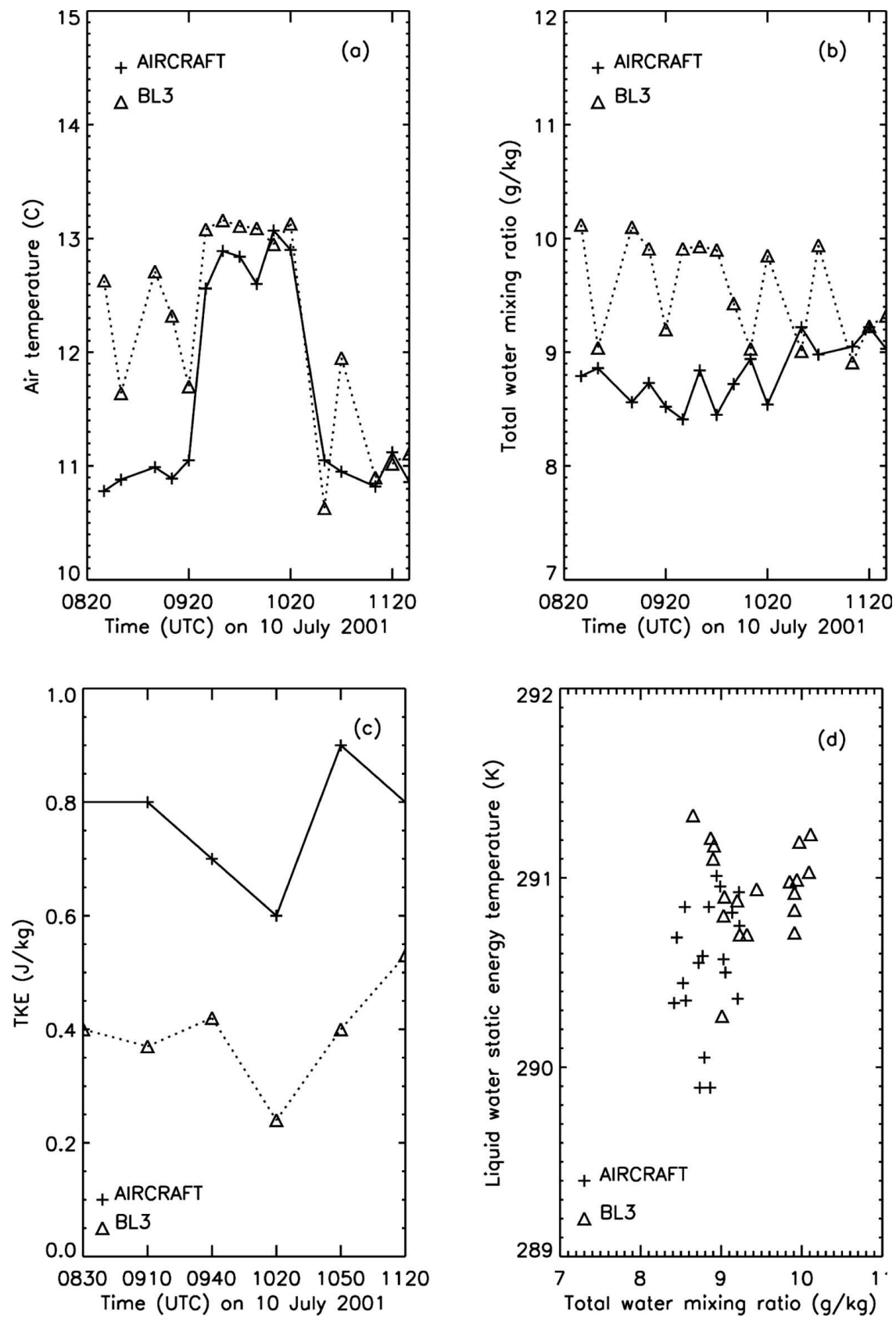

FIG. 5. Time series in a Eulerian framework for the aircraft-observed (plus signs) and simulated (BL3; triangles) (a) temperature $\left(T,{ }^{\circ} \mathrm{C}\right)$, (b) total water mixing ratio $\left(q_{T}, \mathrm{~g} \mathrm{~kg}^{-1}\right)$, (c) TKE $\left(\mathrm{J} \mathrm{kg}^{-1}\right)$, and (d) mixing diagram $\left(T_{L}\right.$ vs $\left.q_{T}\right)$ along flight legs $\mathrm{AB}, \mathrm{CD}$, and $\mathrm{EF}$ (see also Fig. 2).

2005). The mean value of the simulated cloud-layer depth in these flight legs (A-F shown in Fig. 2) was approximately $340 \mathrm{~m}$, the mean LWP was $0.12 \mathrm{~mm}$, and the mean cloud-top cooling was $7 \mathrm{~K} \mathrm{~h}^{-1}$. These model estimates are comparable to those of RF01 mentioned in the foregoing text (Table 4).

Two adiabatic invariants were chosen in order to check the consistency of the model predictions. They are (i) liquid water static energy temperature $\left[T_{L}=\right.$ $\left.\left(T+g z-L_{v} q_{L}\right) / c_{p}\right]$ and (ii) total water mixing ratio $\left(q_{T}\right)$. (See section 4 for a more complete explanation of the variables.) Figure $5 \mathrm{~d}$ shows the mixing diagram $\left(q_{T}\right.$ versus $T_{L}$ ), which indicates that the simulated water mass was almost similar to the observed, especially 
along flight legs $\mathrm{CD}$ and $\mathrm{EF}$, with a slight moisture bias for leg $\mathrm{AB}$. The verification within the Eulerian framework shows that in most of the cases the model simulated essentially the same or a similar air mass.

Similar to the Lagrangian philosophy carried out in some of the previous marine stratocumulus field experiments such as the Atlantic Stratocumulus Transition Experiment (ASTEX; Bretherton and Pincus 1995), quasi-Lagrangian forward trajectories using the simulated three-dimensional airflows were constructed using the flight legs shown in Fig. 2. The trajectories begin at altitudes coinciding with the aircraft measurement position for the corresponding flight legs and are shown in Fig. 6. Simulated thermodynamic variables were extracted along the trajectories for verification.

The differences in the heights of the simulated trajectories against the aircraft trajectories were within $30 \mathrm{~m}$ except for cloud leg EF, where the differences were about $70 \mathrm{~m}$. The mean relative difference, or bias, in air temperature (total water mixing ratio) along the simulated and aircraft trajectories was $5 \%(10 \%)$. The overestimation of the moisture in flight legs $\mathrm{CD}, \mathrm{EF}$, and IJ causes a bias in the mixing ratio of about $1 \mathrm{~g} \mathrm{~kg}^{-1}$. The cloud water mixing ratios were predicted to be nearly double the observed in cloud leg EF. Because of an underestimation of the simulated inversion strength, the air temperature and total water mixing ratio showed average differences of $6^{\circ} \mathrm{C}$ and $4 \mathrm{~g} \mathrm{~kg}^{-1}$ for the trajectories starting from the above-cloud flight leg GH.

Flight leg IJ at the lowest elevation (approximately $80-160 \mathrm{~m}$ ) provided aircraft-measured surface sensible and latent heat fluxes. The simulated trajectory was nearly following the aircraft trajectory in this flight leg. The fairly small sensible heat flux due to the small airsea temperature difference and the magnitude of latent heat flux are in good agreement with the aircraftestimated values in this flight leg (Fig. 7). The mean aircraft estimates of the sensible and latent heat fluxes were 11.7 and $108 \mathrm{~W} \mathrm{~m}^{-2}$, respectively. The corresponding simulated estimates were 10.5 and $96.8 \mathrm{~W} \mathrm{~m}^{-2}$, respectively. On average, a $5 \%$ bias between the observed and simulated SSTs causes a bias of $10 \%-15 \%$ in the heat and moisture fluxes.

In another comparison of tracking the movement of the well-mixed columns, the thermodynamic variables were extracted at the same height as the aircraft observations. The predictions were quite similar to those seen along the simulated trajectories in the subcloud (CD), surface flux (IJ), and above-cloud (GH) flight legs. However, along the forward trajectories starting within the cloud layer, the overestimations of air temperature and water vapor mixing ratios of the air par- cels were within $7 \%$, but the differences between the observed and simulated cloud water amounts were about $60 \%$ because of the overestimation of the cloud depths in flight leg EF (see Fig. 2).

To summarize, the MM5 was able to reproduce the main structure of the marine layer as observed, and the verifications using Eulerian and quasi-Lagrangian frameworks generally agree that the model and the aircraft tracked nearly similar air masses. In this particular case, the consequence of more moisture in the initialization was a $15 \%$ moisture overestimation in the simulated boundary layer during the prognosis. The MM5 was able to simulate only about $50 \%$ of the observed inversion strength because of limitations in the vertical resolution and the inaccuracy of the input synoptic conditions and subsidence.

\section{Thermodynamic energy budget}

To better understand the evolution of the nocturnal cloudy marine boundary layer, we use a scale analysis of the terms of the thermodynamic energy equation to examine the roles of dynamical and physical processes. A depth-averaged thermal energy budget equation to determine the rate of change of $\theta_{e}$ for a column of mixed layer air moving at a mean velocity is given by (Stage and Businger 1981; Stull 1988; Kawa and Pearson 1989; Houze 1993; Koračin et al. 2005)

$$
\begin{aligned}
\int_{0}^{Z_{B}} \frac{d \theta_{e}}{d t} d z= & -\int_{0}^{Z_{B}}\left[\frac{\partial}{\partial z}\left(\overline{w^{\prime} \theta_{e}^{\prime}}\right)+\left(\frac{1}{\rho_{a} c_{p}}\right) \frac{\partial F}{\partial z}\right. \\
& \left.-\frac{L_{v}}{c_{p}} \frac{\partial}{\partial z}\left(\overline{w_{T} q_{L}}\right)\right] d z,
\end{aligned}
$$

where $\theta_{e}$ is equivalent potential temperature, $L_{v}$ is latent heat of vaporization, $c_{p}$ is the specific heat of the air at constant pressure, $\rho_{a}$ is the density of the air, $w$ is the vertical component of the wind velocity, $Z_{B}$ is the mixed layer height (or height of the inversion base), $F$ is the net radiative flux, and $q_{L}$ is the liquid water mixing ratio. The overbar represents a horizontal mean, and the primed quantities are turbulent fluctuations from the mean. Here, $\overline{w^{\prime} \theta_{e}^{\prime}}$ is the kinematic heat flux and $\overline{w_{T} q_{L}}$ is the total liquid water flux due to gravitational settling. The first term on the right-hand side of Eq. (1) represents the buoyancy effects due to entrainment processes and heat fluxes from the surface; the second and third terms represent the rate of heating due to radiation and liquid water effects, respectively. Location PF3 was used to compute the characteristic values of all of the right-hand side terms and compare their sum with the integrated value of the simulated temperature tendency [left-hand side of Eq. (1)]. 

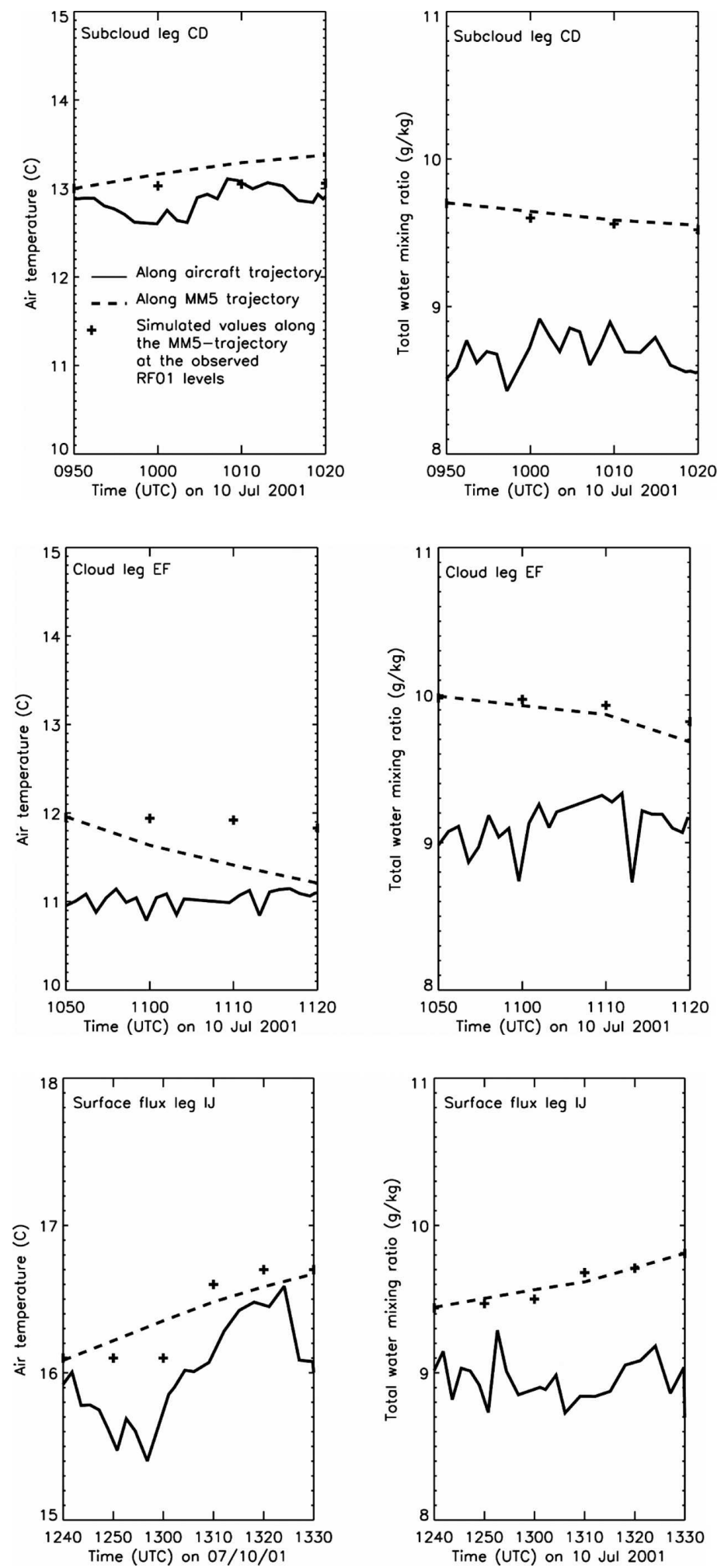

FIG. 6. Time series in a quasi-Lagrangian framework for the air temperature $\left({ }^{\circ} \mathrm{C}\right)$ and total water mixing ratio $\left(\mathrm{g} \mathrm{kg}^{-1}\right)$ for MM5 trajectory altitudes (dashed) and aircraft-measured (solid) values along flight legs $\mathrm{CD}, \mathrm{EF}$, and IJ indicated in Fig. 2. Also plotted are the values along the simulated trajectory at the aircraft level (plus signs). 

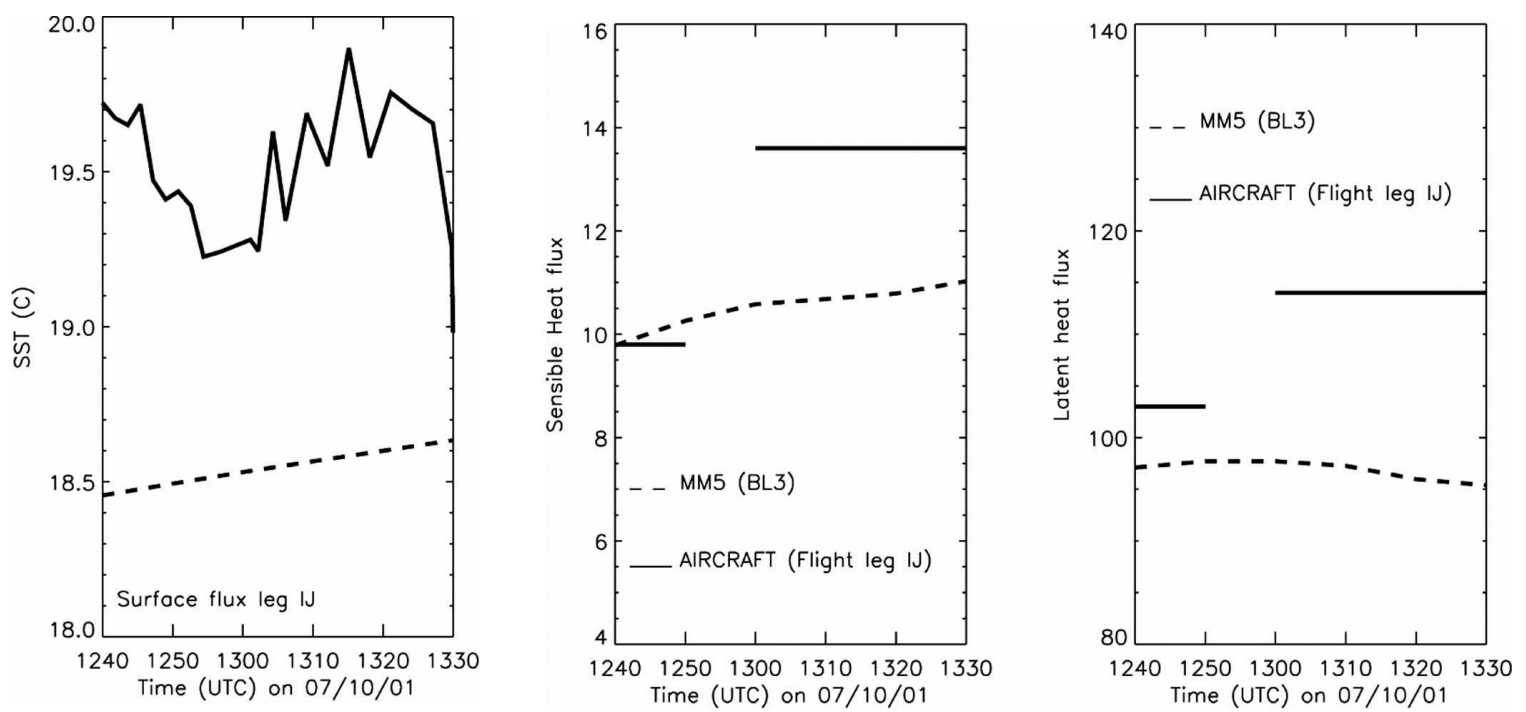

FIG. 7. Same as in Fig. 6 but for SST $\left({ }^{\circ} \mathrm{C}\right)$, and sensible and latent heat fluxes $\left(\mathrm{W} \mathrm{m}^{-2}\right)$ along flight leg IJ.

\section{a. Liquid water fluxes}

To analyze the role of liquid hydrometeors in the thermodynamic energy balance, an alternate method was formulated to diagnose the simulated liquid water fluxes based on mutually independent drop size ranges. We separate the total water content into nonprecipitating types, which is the drop population with diameters of less than $80 \mu \mathrm{m}$ (cloud water), and precipitating types with diameters of 80-300 $\mu \mathrm{m}$ (drizzle) and greater than $300 \mu \mathrm{m}$ (rain). The computational procedure is described in the appendix.

The simulated liquid water content (LWC) for drizzle and the diagnosed liquid water fluxes using Eqs. (A2) and (A7) for the baseline run are shown for profiles PF1-PF4 in Figs. 8a and 8b. The simulated profiles of PF2 and PF3 indicated a pronounced presence of drizzle in the cloud and subcloud layers. The simulated liquid water fluxes are generally comparable to the observed fluxes (Fig. 6 in Stevens et al. 2003a), except that the simulated flux reaches the surface for PF2 and PF3 (the PF2 flux rate is $0.5 \mathrm{~mm} \mathrm{day}^{-1}$ ), whereas there is no observational evidence of drizzle reaching the surface for RF01 (van Zanten et al. 2005). Heating/cooling profiles obtained from the divergence of cloud and drizzle water fluxes using the last term in Eq. (1) are shown in Figs. $8 \mathrm{c}$ and $8 \mathrm{~d}$. The cooling is dominant in the upper part of the cloud and small in the subcloud layer. Also, the drizzle falling through the cloud layer causes incloud latent heating (approximately $0.1-0.3 \mathrm{~K} \mathrm{~h}^{-1}$ ), as well as small amounts of evaporation cooling $(<0.1 \mathrm{~K}$ $\mathrm{h}^{-1}$ ) in the subcloud layer. Near the cloud top, the longwave radiative cooling is the primary mechanism for cooling (approximately 7-8 $\mathrm{K} \mathrm{h}^{-1}$ ) (Table 4 ), compared with the net cooling by liquid water fluxes (approximately $0.2-0.3 \mathrm{~K} \mathrm{~h}^{-1}$ ).

\section{b. Entrainment velocity}

The entrainment velocity $w_{e}$ is computed using the prognostic equation for the evolution of the boundary layer depth $\left(Z_{B}\right)$ following Lilly (1968):

$$
\frac{d Z_{B}}{d t}=w_{e}+w_{m}
$$

where $w_{m}$ is the mean vertical motion computed from the integrated horizontal divergence within the boundary layer. A back-trajectory analysis of the model output is performed with reference to PF3 for $6 \mathrm{~h}$. The entrainment velocity $w_{e}$ is determined based on the mean estimates of boundary layer depths and the vertical motion along the trajectory. The MM5-simulated mean vertical motion at the inversion base [mean vertical motion indirectly calculated using the vertically integrated horizontal divergence in the boundary layer; Stull (1988)] was $-0.87 \mathrm{~cm} \mathrm{~s}^{-1}\left(0.22 \mathrm{~cm} \mathrm{~s}^{-1}\right)$, and the corresponding $w_{e}$ estimate was $1.94 \mathrm{~cm} \mathrm{~s}^{-1}(0.85$ $\mathrm{cm} \mathrm{s}^{-1}$ ). The MM5 overestimated the entrainment velocities compared with the observed value of $\sim 0.35$ $\mathrm{cm} \mathrm{s}^{-1}$ for RF01 (Gerber et al. 2005; Faloona et al. 2005). The underestimation of the strength of the overlying inversion is the likely cause of the overestimation of the entrainment velocity.

Integration of the divergence of the radiative and liquid water flux terms on the right-hand side 

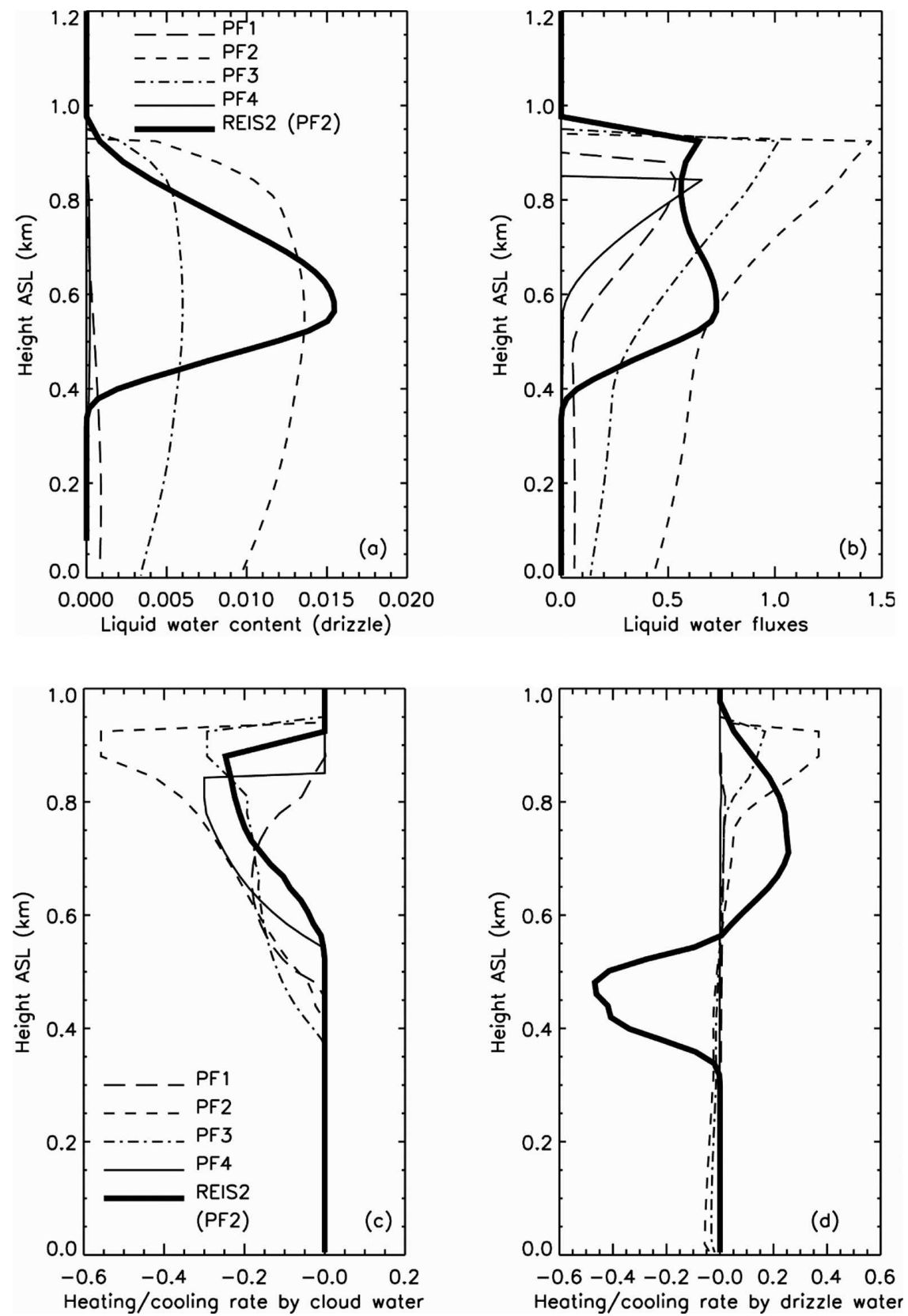

FIG. 8. Simulated profiles at 0800 (PF1), 1140 (PF2), 1230 (PF3), and 1330 UTC (PF4) 10 Jul 2001 for (a) drizzle water content $\left(\mathrm{g} \mathrm{m}^{-3}\right.$ ) using Eq. (A2), (b) total liquid water fluxes (mm day $^{-1}$ ) [sum of the fluxes computed using Eq. (A7) for cloud water and drizzle water], and heating-cooling rates $\left(\mathrm{K} \mathrm{h}^{-1}\right)$ obtained from the last term in Eq. (1) for (c) cloud water fluxes and (d) drizzle water fluxes. The thick solid line indicates the simulated profile for REIS2 at 1140 UTC.

of Eq. (1) was carried out at the points along the trajectory. Figure 9 shows a budget analysis for the time evolution of the source-sink terms on the right-hand side of Eq. (1). Buoyancy appears to be the dominant source term in the heat energy budget. The average contributions of the source (buoyancy and advection) and sink (radiative fluxes and liquid water fluxes) terms were 0.42 and $0.11 \mathrm{~K} \mathrm{~h}^{-1}$, respectively. The average contributions of the radiative and liquid water fluxes were similar. The net effect of the source-sink terms on $\theta_{e}$ is a warming of the boundary layer by $0.3 \mathrm{~K} \mathrm{~h}^{-1}$. 

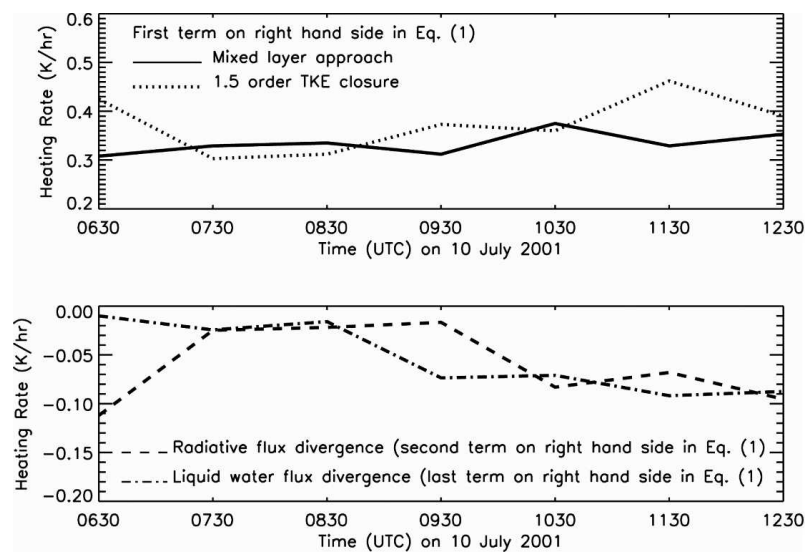

FIG. 9. Time series of the rhs terms in Eq. (1) contributing to the total change in $\theta_{e}\left(\mathrm{~K} \mathrm{~h}^{-1}\right)$ along the back trajectory with an end point at the PF3 location.

\section{Sensitivity experiments}

\section{a. PBL schemes}

Sensitivity experiments BL3, ET3, and BT3 were conducted using three different PBL parameterizations (see Table 1). As seen in the previous section, BL3 generally simulated the thermodynamic characteristics in the marine layer quite well, especially during the later stages of the simulation (Fig. 4). The second-order Burk-Thompson TKE closure scheme in BT3 shows some promise in simulating the inversion strength and mixing in the PBL (Fig. 10); however, both ET3 and BT3 showed a large variability of cloud thickness and sometimes showed unrealistically shallow cloud layers with liquid water amounts greater than $1 \mathrm{~g} \mathrm{~kg}^{-1}$.

Eta Model outputs showed cloud tops significantly warmer than those measured by the aircraft, very weak subsidence above the cloud layer, weak inversion strength, and higher moisture (by $1-2 \mathrm{~g} \mathrm{~kg}^{-1}$ ) in the PBL with the largest values at the surface, compared with aircraft measurements (Fig. 11). However, the MM5 initialized with the Eta Model outputs managed to improve the predictions of the cloud-top parameters and the strength of the marine inversion over time.

A master ensemble obtained from the LES results of profiles for temperature and water substance fields, momentum and heat fluxes, and TKE and its compo-
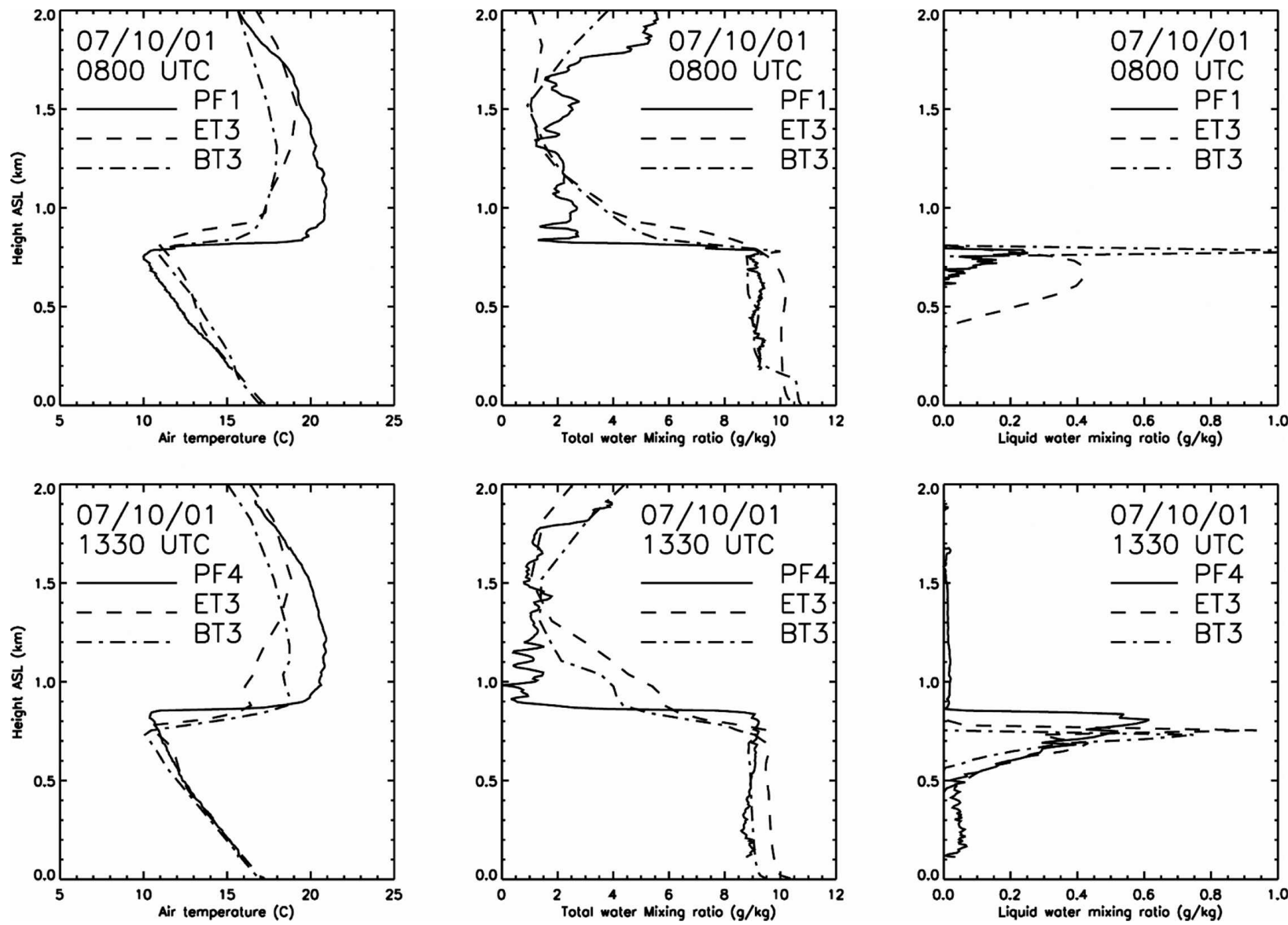

FIG. 10. Same as in Fig. 4 but for BT3 and ET3. 

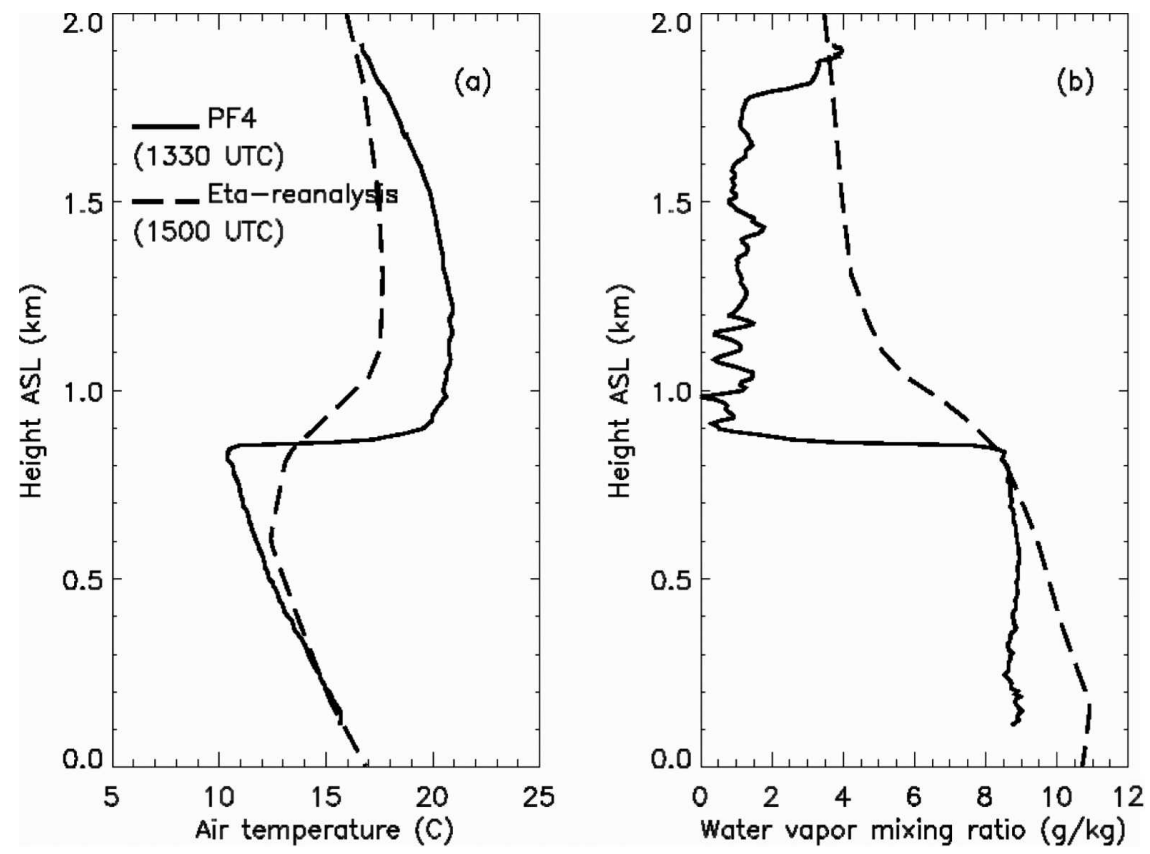

FIG. 11. Observed and Eta Model vertical profiles of (a) temperature $\left({ }^{\circ} \mathrm{C}\right)$ and (b) water vapor mixing ratio $\left(\mathrm{g} \mathrm{kg}^{-1}\right)$ for PF4 on $10 \mathrm{Jul} 2001$.

nents for RF01 was achieved by initializing the various LES models with the ideal conditions that were observed on 10 July 2001 (Stevens et al. 2005). Figure 12 shows the MM5-simulated TKE for profiles PF1-PF4. In general, judging the LES results and observed TKE (see also Fig. 5c) for the flight legs during RF01, the PBL parameterizations in the MM5 underestimate the TKE by a factor of 2. BL3 showed the best agreement for the basic TKE structure of the marine layer among the choices of the PBL schemes. Also, BL3 simulated strong convective mixing due to longwave radiative cooling in the upper part of the cloud layer with the TKE $\left(\sim 0.4 \mathrm{~J} \mathrm{~kg}^{-1}\right)$.

In this particular case, ET3 and BT3 did not simulate the coupling between the radiative and boundary layer processes well; that is, for the MM5-simulated clouds for ET3 and BT3, the locations of the clouds and the strong radiative cooling in the vertical were out of place. ET3 simulated turbulence in the cloud layer $\left(\sim 0.4 \mathrm{~J} \mathrm{~kg}^{-1}\right)$ corresponding to the radiative cooling $\left(\sim 200 \mathrm{~K} \mathrm{day}^{-1}\right)$ during the first $12 \mathrm{~h}$ of the model simulation. A rapid mixing occurred in the marine layer during this time (virtual potential temperature profiles are nearly uniform with height). Although, clouds and radiative cooling were present in the cloud layer in ET3 during the entire simulation period, turbulence was absent in the cloud layer after the first $12 \mathrm{~h}$. Also, BT3 showed a large variability in the TKE vertical structure, and did not reproduce accurate cloud-driven turbulence compared with the LES results for RF01.

Vertical $X-Z$ cross sections of TKE, cloud mixing ratio, winds, and potential temperature for the MM5 runs with all TKE closure schemes are shown in Fig. 13. It is apparent that BL3 simulated the expected structure of the cloud-driven turbulence and cloud water. Among the PBL schemes used in this study, the Gayno-Seaman PBL scheme (Ballard et al. 1991; Gayno et al. 1994) is the only scheme where a liquid water-conserving variable, that is, liquid water potential temperature (Betts 1973), was used to evaluate the buoyancy fluxes, whereas ET3 and BT3 use virtual potential temperature. From the point of view of operational forecasting, the significance of the correspondence between the physical parameterizations in the model is rather crucial.

\section{1) TKE BUdGet}

The main components of the total change of TKE $(E)$ following the air motion are symbolically described as

$$
\frac{d E}{d t}=S+B+T+D
$$

where $S$ represents shear production, $B$ represents buoyancy production-consumption, $T$ represents the 

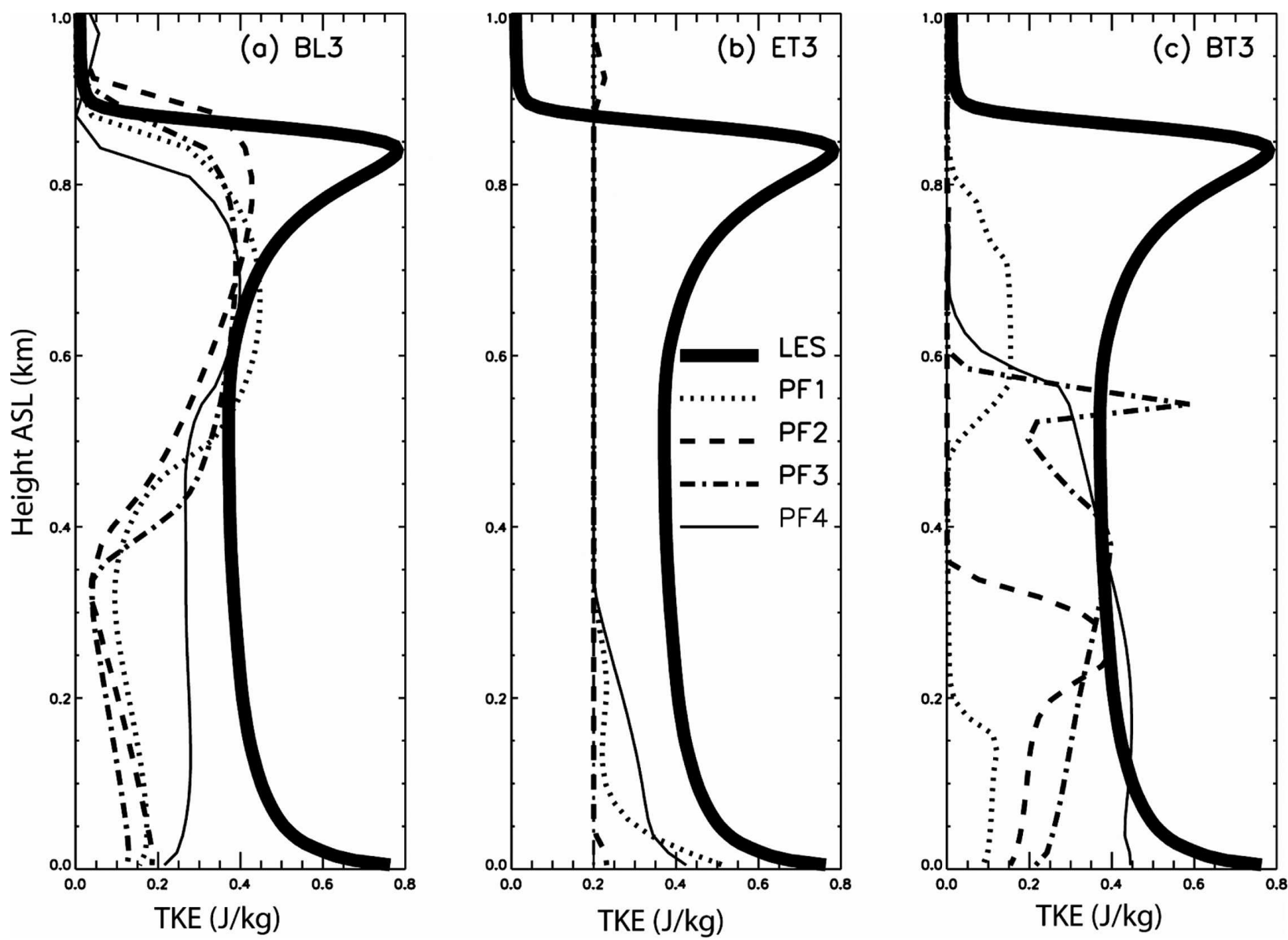

FIG. 12. Simulated TKE (J kg $\left.{ }^{-1}\right)$ at 0800 (PF1), 1140 (PF2), 1230 (PF3), and 1330 UTC (PF4) 10 Jul 2001 for the (a) BL3, (b) ET3, and (c) BT3 turbulence parameterization schemes. Also shown is the TKE profile from the LES master ensemble for RF01 (Stevens et al. 2005).

turbulence transport, and $D$ represents the viscous dissipation. Figure 14 shows simulated profiles of the individual components of the TKE equation for BL3, $\mathrm{BT} 3$, and ET3 at the PF2 and PF3 locations. Among the choices of TKE closure schemes, the BL3-simulated budget components clearly resemble the distinct features of the previous TKE budget studies on stratocumulus-topped boundary layers (Brost et al. 1982; Deardorff 1980). BL3 showed an unstable marine cloud layer with the buoyancy production $(B)$ of turbulence by radiative cooling displayed in all profiles (PF1 not shown), and a local balance of shear production $(S)$ and viscous dissipation $(D)$ in the subcloud layer during the early stage of the simulation. The sharp jumps in the velocity field at the cloud base and top cause local maxima of $S$ in the profiles. At the early stage of the simulation ( $\sim 30 \mathrm{~h}$ into the model simulation), the entrained air reduces the LWC and lowers the rate of radiative cooling, which then stabilizes the cloud layer. With weaker $S$ at the cloud top in PF2, the predicted maximum liquid water mixing ratio was $0.8 \mathrm{~g} \mathrm{~kg}^{-1}$; the stronger $S$ in PF3 predicted $0.6 \mathrm{~g} \mathrm{~kg}^{-1}$. Figure 14 also shows that BT3 simulates only occasional buoyancy, and mainly in the subcloud layer. The ET3 scheme shows unrealistic negligible buoyancy throughout the boundary layer for the RF01 case.

\section{2) MM5 versus LES TURbulENCE BUdGETS}

The mean profiles of the individual components of the TKE equation obtained from the LES ensembles for RF01 (see Stevens et al. 2005) are shown in Fig. 15. The RF01 LES mean ensemble profiles show buoyancy production to be dominant inside the cloud layer, shear production to be dominant near the surface, and upward (downward) transport of TKE at the cloud base and top (in the cloud layer). The closest BL3 $\theta_{L}$ sounding that is in good agreement with the LES ensembles and aircraft measurements was PF4, and therefore it was chosen to compare the MM5-simulated and the 

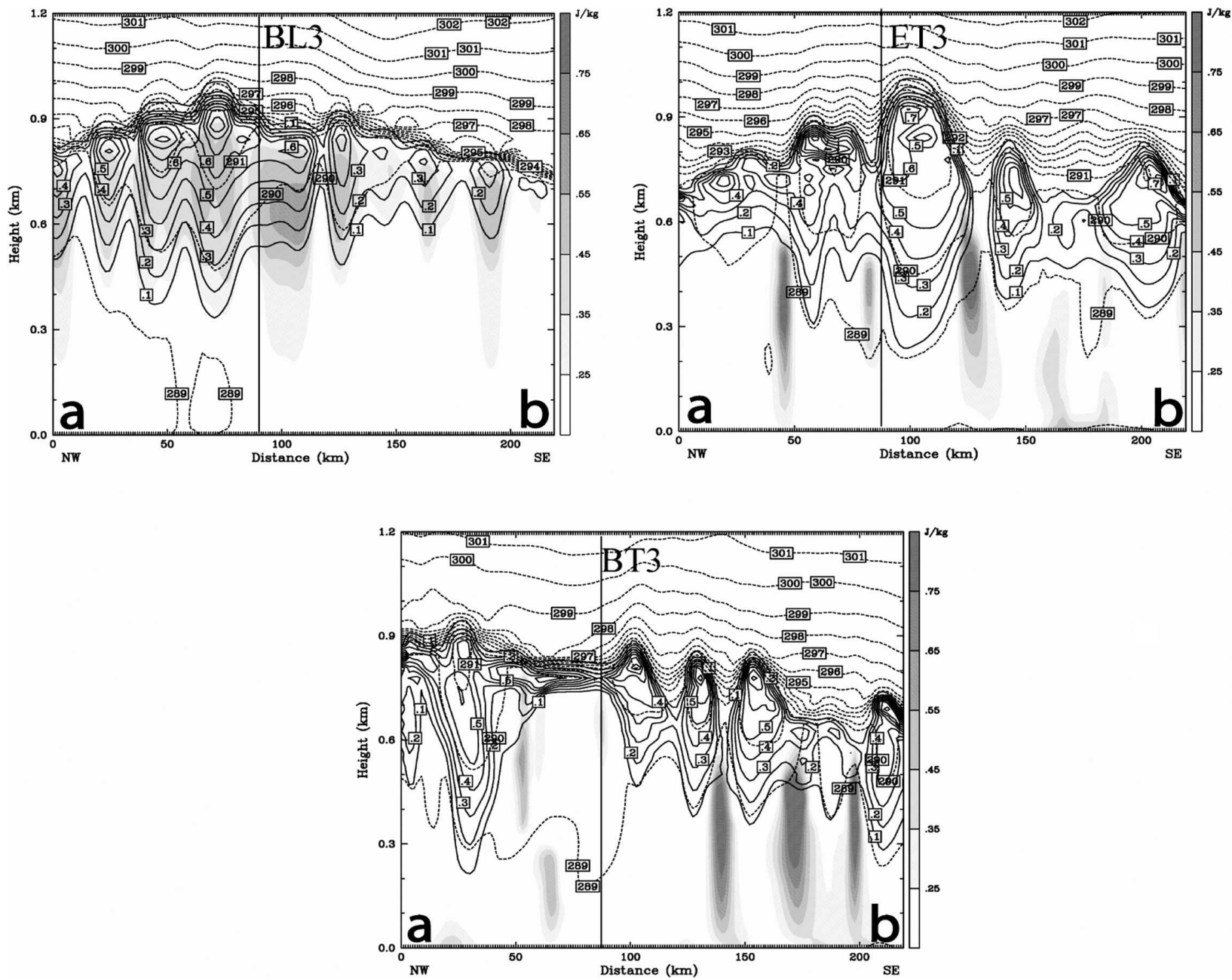

FIG. 13. MM5 predictions of the $X-Z$ cross section of TKE $\left(\mathrm{J} \mathrm{kg}^{-1}\right.$, shaded), cloud water mixing ratio $\left(\mathrm{g} \mathrm{kg}^{-1}\right.$, contour interval $=$ $0.1)$, and potential temperature $(\mathrm{K}$, dashed; contour interval $=1)$ along the mean aircraft track of the DYCOMS-II target area (see Figs. $1 \mathrm{a}$ and $1 \mathrm{~b}$ ) at $0800 \mathrm{UTC} 10 \mathrm{Jul} 2001$ (PF1) for the BL3, ET3, and BT3 simulations. The vertical line indicates the approximate location close to PF1 as seen in Fig. 1b.

ensemble-mean LES profiles of the TKE budget components for RF01. The LES mean $\theta_{L}$ estimates in the PBL were slightly larger than the observed by a degree or less (Fig. 15). The vertically integrated values of the buoyancy and transport terms of Eq. (3) simulated by BL3 were 0.25 and $0.005 \mathrm{~m}^{3} \mathrm{~s}^{-3}$, which are comparable to the LES estimates of 0.33 and $0.005 \mathrm{~m}^{3} \mathrm{~s}^{-3}$; however, the dissipation is largely overestimated as a consequence of shear overestimation.

\section{b. Sensitivity to microphysical schemes}

Sensitivity experiments were performed using two other choices of microphysical parameterizations (REIS2 and SCH3; see Table 1). There are two options in the MM5 to use Reisner's explicit microphysics
(Reisner et al. 1998). The parameterization of warm cloud microphysics is similar for both options, except in the representation of the autoconversion processes. The evolution of precipitable hydrometeors (rain or drizzle) is based on a threshold cloud water mixing ratio $\left(0.5 \mathrm{~g} \mathrm{~kg}^{-1}\right)$ for the first option [used in BL3; Kessler (1969)], and based on the number concentration of cloud drops $\left(N_{c}\right)$ for the second option [the simulation with this option is referred to as REIS2; Walko et al. (1995)]. The representation of cloud microphysics in SCH3 (Schultz 1995) is somewhat similar to the first option.

REIS2 simulated precipitable water mixing ratios $\left(q_{r}\right)$ of less than $0.02 \mathrm{~g} \mathrm{~kg}^{-1}$ in all of the simulated profiles. Such low mixing ratios consist primarily of 

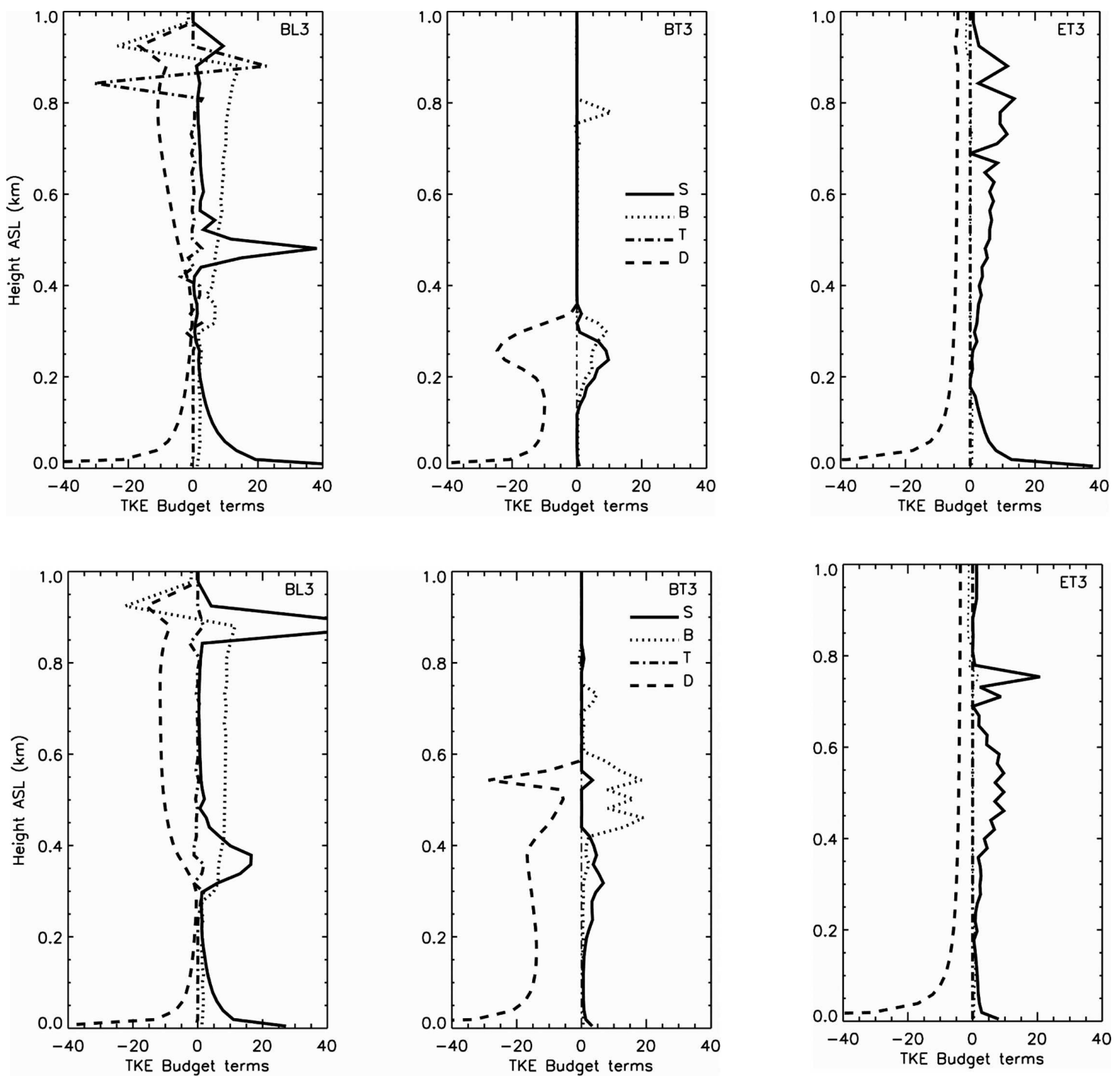

FIG. 14. Simulated TKE kinematic budget terms $\left(\times 10^{4}, \mathrm{~m}^{2} \mathrm{~s}^{-3}\right)$ at (top) 1140 (PF2) and (bottom) 1230 UTC (PF3) 10 Jul 2001: B, buoyancy production; $\mathrm{S}$, shear production; $\mathrm{T}$, turbulent transport; and $\mathrm{D}$, viscous dissipation.

drizzle water (Young 1993). REIS2 induces evaporation of drizzle water too rapidly less than $100 \mathrm{~m}$ below the cloud base (Fig. 8a). There were no traces of drizzle reaching the surface for simulated profiles PF1-PF4, which agrees well with the observed water content profiles (Fig. 6 of Stevens et al. 2003a). This implies that a simple Kessler-type autoconversion is not advisable for simulating the evolution of precipitable water substances in the marine-layer clouds. In some of the profiles, REIS2 also predicted larger TKE amounts $(\sim 0.6$ $\mathrm{J} \mathrm{kg}^{-1}$ ) and enhanced decoupling in the cloud layer compared to BL3 (figure not shown). The drizzle falling through the cloud layer causes an in-cloud latent heating rate of about $0.3 \mathrm{~K} \mathrm{~h}^{-1}$ and a cooling rate of 0.5 $\mathrm{K} \mathrm{h}^{-1}$ below the cloud base caused by evaporation (Fig. 8d). Evaporative cooling in the subcloud layer decouples the subcloud and cloud layers with respect to the turbulence structure.

$\mathrm{SCH} 3$ showed no indications of precipitable water, and the simulated cloud water mixing ratios were less than the threshold value of $0.5 \mathrm{~g} \mathrm{~kg}^{-1}$ in all of the simulated profiles. $\mathrm{SCH} 3$ showed shallower clouds 

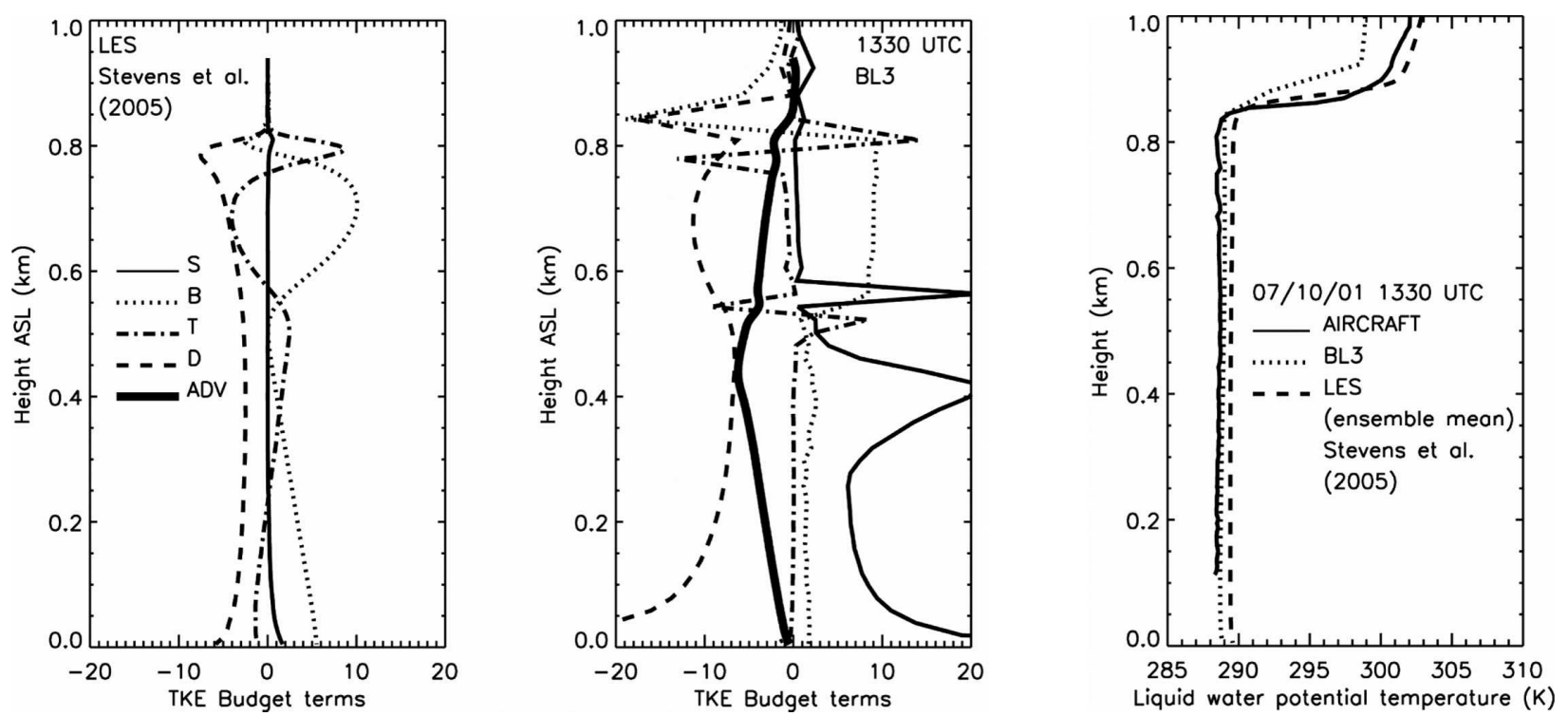

FIG. 15. Same as in Fig. 14 but for 1330 UTC (PF4), and LES ensemble mean TKE budgets. Also shown are the liquid water potential temperature $(\mathrm{K})$ profiles at the same time from aircraft observations and model simulations. ADV $=$ advection components.

$(50-100 \mathrm{~m})$ in the simulation, and produced TKE as much as double $\left(\sim 1.6 \mathrm{~J} \mathrm{~kg}^{-1}\right)$ in the cloud layer compared with the LES estimates for RF01. The likely cause of this turbulence is the rapid cooling at the cloud top $\left(\sim 8 \mathrm{~K} \mathrm{~h}^{-1}\right)$ and warming (more than a $\left.1^{\circ} \mathrm{h}^{-1}\right)$ at the cloud base by longwave radiative fluxes. The preliminary investigation seems to indicate that REIS2 shows promise for better simulation of the RF01 ma-
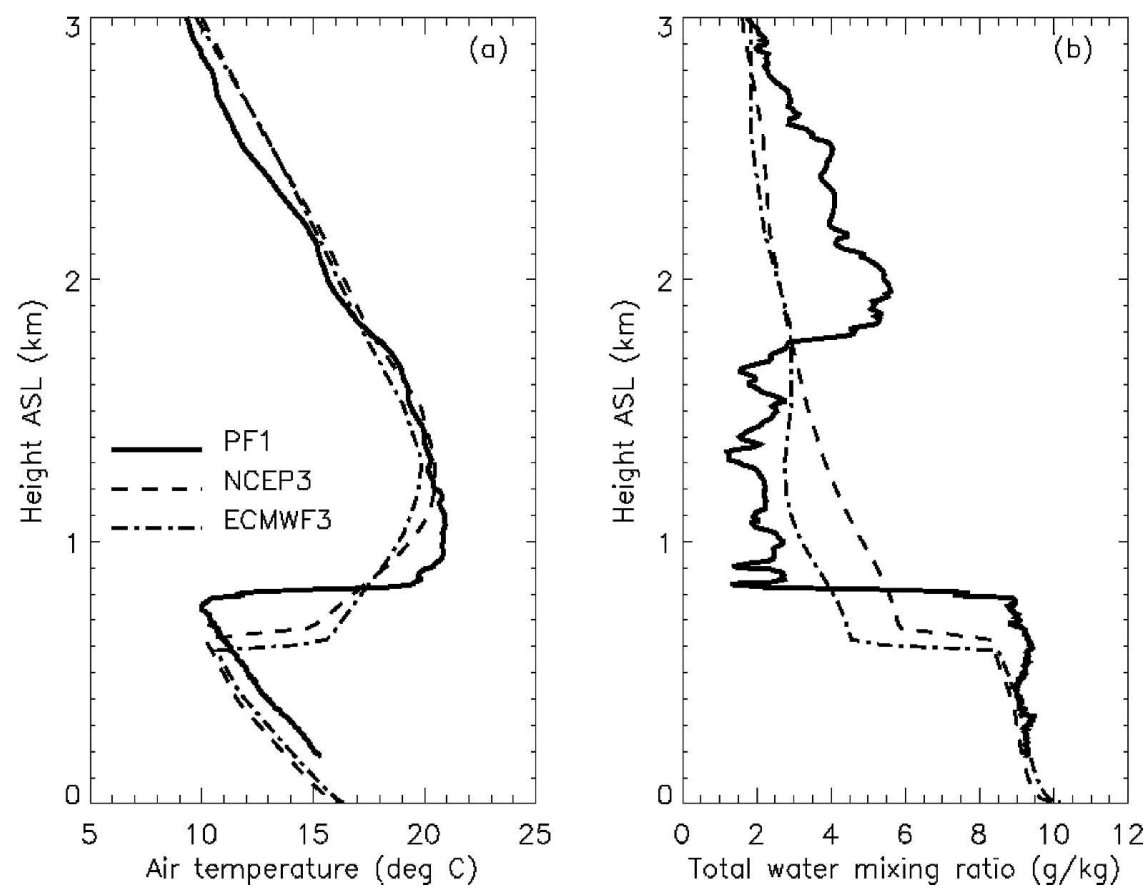

FIG. 16. Observed and model vertical profiles of (a) air temperature $\left({ }^{\circ} \mathrm{C}\right)$ and (b) water vapor mixing ratio $\left(\mathrm{g} \mathrm{kg}^{-1}\right)$ for PF1 on $10 \mathrm{Jul} 2001$ obtained from the NCEP3 (first-guess analysis fields, NCEP-NCAR dataset) and ECMWF3 (first-guess analysis fields, ECMWF dataset) simulations. 
rine-layer fields. However, further examination is under way to assess the causes of decoupling of the cloud and subcloud layers.

Aircraft observations during RF01 reported cloud drop concentrations of $N_{c}=140 \mathrm{~cm}^{-3}$ (Table 3 of van Zanten et al. 2005). A suggested fixed value of $N_{c}\left(=100 \mathrm{~cm}^{-3}\right)$ was used in the simulations shown in Table 1 (Thompson et al. 2004). A sensitivity test was conducted using a larger value of $N_{c}\left(=150 \mathrm{~cm}^{-3}\right)$ in the baseline setup (referred to as N150). There were no significant differences in the predicted temperature and vapor mixing ratio profiles between BL3 and N150. In general, an increase in $N_{c}$ by $50 \mathrm{~cm}^{-3}$ in the baseline setup reduces the drizzle amounts by $50 \%-60 \%$, which is also consistent with the previous model findings on drizzle formation (Nicholls 1987; Austin et al. 1995; Khairoutdinov and Kogan 2000). The Kessler scheme used in BL3 does not directly include the effect of $N_{c}$. However, it appears that $N_{c}$ acts indirectly through the cloud field with the choice of Gayno-Seaman PBL scheme because of its formulation based on conserved variables of saturated atmosphere (J. Dudhia 2005, personal communication).

\section{c. Sensitivity to initialization}

The NCEP3 and ECMWF3 simulations (in which data from the NCEP-NCAR and ECMWF reanalyses at $2.5^{\circ} \times 2.5^{\circ}$ resolution were used for first-guess fields) largely underestimated the inversion base heights by $20 \%-30 \%$ (Fig. 16). The mean inversion base height simulated by NCEP3 (ECMWF3) was $647 \mathrm{~m}$ (594 m) compared with the observed mean value of $828 \mathrm{~m}$ (Table 4). The trade-off between the two sources of initial analysis fields is that the simulations initialized using the NCEP-NCAR (Eta) analysis better predict the temperature structure above (below) the inversion layer. The subsidence forcing is better represented in the NCEP-NCAR analysis fields (figure not shown). The gray area to all the choices of analysis fields is in the predictions of the inversion layer and the inversion strength. The cold and wet biases near the surface bring humidity values greater than $90 \%$. It is obvious that substantial improvements in the initialization of the marine-layer thermodynamic structure are necessary for better accuracy in the offshore forecasts of the marine layer. Some recent studies have emphasized that the boundary layer depths inferred from satellitederived low-level cloud data could be assimilated into the model initialization for better short-term predictions of boundary layer structure and inversion strength (Koračin et al. 2003; Vellore et al. 2006).

\section{Conclusions}

The present study has located some of the major problems in the mesoscale forecasting of the marine layer via critical evaluation of the selection of the initial and boundary conditions as well as the physical parameterizations.

We tested three input fields (Eta, NCEP-NCAR, and ECMWF), and all three fields show deficiencies, mainly in the persistent overestimation of the boundary layer moisture and imprecise estimations of the thermodynamic structure in the boundary layer and in the free troposphere aloft. Although the MM5 was able to simulate an overall structure of the marine layer that was comparable to the airborne observations, the marinelayer depths were overpredicted by $10 \%$ using the finer Eta Model reanalysis fields, whereas they were underestimated by $20 \%-30 \%$ when coarser reanalysis fields (NCEP-NCAR, ECMWF) were used for initialization. The Eta-reanalyzed mean surface water vapor mixing ratio was $11.2 \mathrm{~g} \mathrm{~kg}^{-1}$, whereas the observed value at the nearest buoy station, the Tanner Banks buoy, located approximately $200 \mathrm{~km}$ east of the DYCOMS II target area, was $9.01 \mathrm{~g} \mathrm{~kg}^{-1}$; that is, the Eta fields placed more moisture in the DYCOMS II area by $25 \%$ compared with the buoy observations. On average, the consequence of this is that moisture (cloud depths) in the boundary layer is overpredicted by $15 \%(65 \%)$. In spite of the fact that vertical spacing as small as $25 \mathrm{~m}$ was used to resolve the marine-layer structure, MM5 was able to simulate only about $50 \%$ of the observed inversion strength because of the uncertainties in the initialized thermodynamic structure above the marine layer. The entrainment velocities were overestimated as a consequence of the weak simulated inversion strength.

The sensitivity tests have shown that the selections of turbulence and cloud microphysical schemes significantly influence the turbulence estimates and cloud parameters. Regarding the turbulence parameterizations, two of the tested schemes (Eta PBL and BurkThompson) were not able to reproduce the clouddriven turbulence and coupling with radiation processes. The Gayno-Seaman PBL scheme compared much better than the other two schemes with the LES and aircraft measurements, especially in terms of buoyancy and transport processes for the TKE budget. The magnitudes of the predicted turbulence estimates were about $50 \%$ of those obtained from the LES results and observed aircraft estimates. The main reason is that the Gayno-Seaman scheme is the only parameterization that uses advective processes and a liquid waterconserving variable (i.e., liquid water potential temperature), which facilitates better interaction between 
the turbulence fluxes and clouds. The rationale behind the excess/deficit in the turbulence budgets has to be further investigated.

The present study indicates that the cooling effect of the water species also appears to be a significant thermal energy component of the growth of the marine boundary layer. The magnitudes of the simulated liquid water fluxes are generally comparable with the observed, except that in some instances the simulated fluxes reach the ground, which was not evidenced in the aircraft observations. Because of overestimation of the moisture in the analysis fields and model predictions, further investigation is necessary to identify the water sources in order to substantiate this modeled evidence. The microphysical parameterization that uses the number concentration of cloud drops in the autoconversion process simulates a realistic evolution of the precipitable hydrometeors in the cloudy marine layer on the positive side; however, it enhances the decoupling in the turbulence structure.

Major results that can be used for guidance in operational forecasting include the following.

- The initial conditions obtained from the outputs of coarse grid models do not accurately represent the thermodynamic structure in the lowest $1500 \mathrm{~m}$. The Eta, NCEP-NCAR, and ECMWF reanalysis fields showed much shallower and significantly moister marine layer compared with the aircraft observations. Also, all three of the input fields show warmer inversion bases (or cloud tops) compared with the satellite observations. From an operational forecasting point of view, assimilating satellite-derived low-level cloud products into the mesoscale models using currently available and future methodologies will produce considerable improvement in the model initialization for coastal and offshore regions.

- Turbulence was generally significantly underestimated and most of the tested turbulence parameterizations did not exhibit coupling with radiation (cloud-top radiative cooling, in particular). Turbulence schemes that use water-conserving variables (liquid water potential temperature) should be definitely preferred and incorporated into current and future mesoscale models.

- Simpler microphysical schemes do not represent hydrometeors adequately (especially the occurrence of drizzle) and significantly affect the simulated thermodynamic structure of the marine boundary layer. It is preferable to use cloud microphysical parameterizations in which the number concentration of cloud drops is used in the autoconversion of cloud water to drizzle/rain for simulating drizzle processes.
The results of the present study confirm that utilization of satellite data and ensemble forecasting are ideal candidates for the betterment of operational mesoscale forecasting (Eckel and Mass 2005; Vellore et al. 2006). Further investigation is presently under way. The newgeneration modeling systems such as the Weather Research Forecasting (WRF; Skamarock et al. 2005) model have choices of the physical parameterizations that are similar to those used in this study. Consequently, some of our results are directly applicable to operational MM5 and WRF forecasting systems for improvements in marine-layer forecasting.

Acknowledgments. This study was supported by Office of Naval Research Grants N00014-01-1-0663 and N00014-01-1-0295, and National Science Foundation Grant NSF-OCE 9907884. The authors express special appreciation to Dr. Jordan Powers, Dr. Jimy Dudhia, and mesouser utility support at NCAR for their valuable suggestions during the course of this research work, and Travis McCord of the Desert Research Institute (DRI) for technical preparation of the manuscript. The authors gratefully acknowledge the DYCOMS II database for aircraft data, satellite images, and LES results, and the Advanced Computing in Environmental Science program (ACES) of DRI for their computer resources. Constructive critical comments and suggestions by anonymous reviewers significantly improved the manuscript.

\section{APPENDIX}

\section{Liquid Water Fluxes}

The following formulation is used to diagnose the liquid water fluxes based on the drop size ranges. To be consistent with the MM5 parameterization, the drop size distribution is assumed to be exponential following Marshall and Palmer (1948):

$$
N(D)=N_{o} e^{-\lambda D}
$$

where $N_{o}$ and $\lambda$ are the intercept and slope parameters of the distribution. Here, $N(D)$ is the concentration of drops in the diameter interval $D$ to $D+d D$. The LWC $\left(\mathrm{kg} \mathrm{m}^{-3}\right)$ is partitioned from the total water content with respect to diameter ranges for cloud water $(D<80$ $\mu \mathrm{m})$, drizzle $(80<D<300 \mu \mathrm{m})$, and rain $(D \geq 300$ $\mu \mathrm{m})$, and is defined as follows:

$$
\mathrm{LWC}=\rho_{w} \int_{D_{\min }}^{D_{\max }}\left(\frac{\pi D^{3}}{6}\right) N(D) d D,
$$

where $D_{\min }$ and $D_{\max }$ are the minimum and maximum values of the size ranges, respectively (Rogers and Yau 
1989; Duynkerke et al. 1999), and $\rho_{w}$ is the density of water. The number concentration, $N_{x}$, is an integral measure of this distribution over the spectrum of drop sizes; that is,

$$
N_{x}=\int_{D_{\min }}^{D_{\max }} N(D) d D
$$

where subscript $x=c$ or $x=d$ represent cloud and drizzle drops, respectively. The size ranges for the cloud water and rainwater were determined by comparing their simulated mixing ratios and LWC using Eq. (A2). Theoretically, drizzle produces terminal fall speeds between 0.2 and $2 \mathrm{~m} \mathrm{~s}^{-1}$, and large rain mixing ratios $\left(>0.1 \mathrm{~g} \mathrm{~kg}^{-1}\right)$ produce terminal fall speeds between 2 and $8 \mathrm{~m} \mathrm{~s}^{-1}$ (Young 1993). In this study, the simulated rain mixing ratios were much smaller than $0.1 \mathrm{~g} \mathrm{~kg}^{-1}$, and the fall speeds of the rainwater were less than 2 $\mathrm{m} \mathrm{s}^{-1}$. Therefore, the simulated rainwater primarily

$$
N_{o}=\left\{\begin{array}{l}
N_{c} \lambda_{c}\left(1-e^{-80 \times 10^{-6} \lambda_{c}}\right)^{-1}, \\
1 \times 10^{10},
\end{array}\right.
$$

The final expression for the liquid water flux in Eq. (1) is then defined as follows (Brost et al. 1982; Nicholls 1984):

$$
\begin{aligned}
-\overline{w_{T} q_{L}}= & \frac{\rho_{w}}{\rho_{a}} \int_{D_{\min }}^{D_{\max }}\left(\frac{\pi D^{3}}{6}\right) w_{T}(D) N(D) d D \\
& -\overline{w_{T} q_{L}}=10^{-5} \mathrm{~m} \mathrm{~s}^{-1} \equiv 1 \mathrm{~mm} \mathrm{day}^{-1} .
\end{aligned}
$$

\section{REFERENCES}

Austin, P., Y. Wang, R. Pincus, and V. Kujala, 1995: Precipitation in stratocumulus clouds: Observation and modeling results. $J$. Atmos. Sci., 52, 2329-2352.

Ballard, S. P., B. W. Golding, and R. N. B. Smith, 1991: Mesoscale model experimental forecasts of the Haar of northeast Scotland. Mon. Wea. Rev., 119, 2107-2123.

Beardsley, R. C., C. E. Dorman, C. A. Friehe, L. K. Rosenfield, and C. D. Wyant, 1987: Local atmospheric forcing during the Coastal Ocean Dynamics Experiment I: Description of the boundary layer and atmospheric conditions over a north California upwelling region. J. Geophys. Res., 92, 1467-1488.

Betts, A. K., 1973: Non-precipitation cumulus convection and its parameterization. Quart. J. Roy. Meteor. Soc., 99, 178-196.

Bretherton, C. S., and R. Pincus, 1995: Cloudiness and marine boundary layer dynamics in the ASTEX Lagrangian experiments. J. Atmos. Sci., 52, 2707-2723.

Brost, R. A., J. C. Wyngaard, and D. H. Lenschow, 1982: Marine contained drizzle drops. The fall speeds $\left(w_{T}\right)$ for the cloud and drizzle drops ( $D$ given in $\mathrm{m}$ ) are given by

$$
w_{T}(D)=\left\{\begin{array}{ll}
3 \times 10^{7} D^{2}, & \mathrm{~m} \mathrm{~s}^{-1} \text { for the cloud drops } \\
4 \times 10^{3} D, & \mathrm{~m} \mathrm{~s}^{-1} \text { for the drizzle drops }
\end{array} .\right.
$$

The slope parameter $\lambda$ in Eq. (A1) for cloud and drizzle drops is given by

$$
\begin{aligned}
\lambda_{c} & =\left(\frac{\pi \rho_{w} N_{c}}{\rho_{a} q_{c}}\right)^{1 / 3} \text { and } \\
\lambda_{d} & =\left(\frac{\pi \rho_{w} N_{o}}{\rho_{a} q_{r}}\right)^{1 / 4},
\end{aligned}
$$

where $N_{c}$ is the total number concentration of cloud droplets, $\rho_{a}$ is the density of air, and $q_{r}$ is the precipitable water mixing ratio. The intercept parameter $N_{o}$ in Eq. (A1) is considered as follows:

$\mathrm{m}^{-4}$ for the cloud drops
$\mathrm{m}^{-4}$ for the drizzle drops

stratocumulus layers. I: Mean conditions. J. Atmos. Sci., 39, 800-817.

Burk, S. D., and W. T. Thompson, 1989: A vertically nested regional numerical weather prediction model with secondorder closure physics. Mon. Wea. Rev., 117, 2305-2324.

Cressman, G. P., 1959: An operational objective analysis system. Mon. Wea. Rev., 87, 367-374.

Deardorff, J. W., 1980: Stratocumulus-capped mixed layers derived from a three-dimensional model. Bound.-Layer Meteor., 18, 495-527.

Driedonks, A. G. M., and P. G. Duynkerke, 1989: Current problems in the stratocumulus-topped atmospheric boundary layer. Bound.-Layer Meteor., 46, 275-304.

Dudhia, J., 1989: Numerical study of convection observed during the Winter Monsoon experiment using a mesoscale twodimensional model. J. Atmos. Sci., 46, 3077-3107.

Duynkerke, P. G., and Coauthors, 1999: Inter-comparison of three- and one-dimensional model simulations and aircraft observations of stratocumulus. Bound.-Layer Meteor., 92, 453-487.

Eckel, F. A., and C. F. Mass, 2005: Aspects of effective mesoscale, short-range ensemble forecasting. Wea. Forecasting, 20, 328 350.

Faloona, I., and Coauthors, 2005: Observations of entrainment in eastern Pacific marine stratocumulus using three conserved scalars. J. Atmos. Sci., 62, 3268-3285.

Friehe, C. A., S. P. Burns, D. Khelif, and X. Song, 1996: Meteorological and flux measurements from the NOAA WP3D aircraft in TOGA COARE. Preprints, Eighth Conf. on AirSea Interaction and Conf. on the Global Ocean-AtmosphereLand System (GOALS), Atlanta, GA, Amer. Meteor. Soc., J42-J45.

Gayno, G. A., N. L. Seaman, A. M. Lario, and D. R. Stauffer, 1994: Forecasting visibility using a 1.5 -order closure bound- 
ary layer scheme in a 12-km nonhydrostatic model. Preprints, 10th Conf. on Numerical Weather Prediction, Portland, OR, Amer. Meteor. Soc., 18-20.

Gerber, H., G. Frick, S. P. Malinowski, J.-L. Brenguier, and F. Burnet, 2005: Holes and entrainment in stratocumulus. J. Atmos. Sci., 62, 443-459.

Grell, G. A., J. Dudhia, and D. R. Stauffer, 1995: A description of the fifth-generation Penn State/NCAR Mesoscale Model (MM5). NCAR Tech. Note TN-398+STR, 122 pp. [Available online at http://www.mmm.ucar.edu/mm5/doc1.html.]

Houze, R. A., 1993: Cloud Dynamics. Academic Press, 573 pp.

Hu, Y. X., and K. Stamnes, 1993: An accurate parameterization of the radiative properties of water clouds suitable for use in climate models. J. Climate, 6, 728-742.

Janjić, Z. I., 1994: The step-mountain Eta coordinate model: Further developments of the convection, viscous subcloud layer, and turbulence closure schemes. Mon. Wea. Rev., 122, 927945.

- 1996: The Mellor-Yamada 2.5 scheme in the NCEP Eta Model. Preprints, 11th Conf. on Numerical Weather Prediction, Norfolk, VA, Amer. Meteor. Soc., 333-334.

Kain, J. S., 2004: The Kain-Fritsch convective parameterization: An update. J. Appl. Meteor., 43, 170-181.

_ mesoscale models: The Kain-Fritsch scheme. The Representation of Cumulus Convection in Numerical Models, Meteor. Monogr., No. 46, Amer. Meteor. Soc., 165-170.

Kawa, S. R., and R. Pearson, 1989: An observational study of stratocumulus entrainment and thermodynamics. J. Atmos. Sci., 46, 2649-2661.

Kessler, E., III, 1969: On the Distribution and Continuity of Water Substance in Atmospheric Circulations. Meteor. Monogr., No. 32, Amer. Meteor. Soc., 89 pp.

Khairoutdinov, M. F., and Y. L. Kogan, 2000: A new cloud physics parameterization in a large eddy simulation model of marine stratocumulus. Mon. Wea. Rev., 128, 229-243.

Koračin, D., and C. Dorman, 2001: Marine atmospheric boundary layer divergence and clouds along California in June 1996. Mon. Wea. Rev., 129, 2040-2056.

_- J. Lewis, W. T. Thompson, C. E. Dorman, and J. A. Businger, 2001: Transition of stratus into fog along the California coast: Observations and modeling. J. Atmos. Sci., 58, 1714-1731.

— J. Powers, M. Wetzel, S. Chai, and N. Adhikari, 2003: Improving prediction of the marine coastal clouds using satellite and aircraft data. Preprints, Fifth Conf. on Coastal Atmospheric Prediction and Processes, Seattle, WA, Amer. Meteor. Soc., 138-140.

, C. E. Dorman, and E. P. Dever, 2004: Coastal perturbations of marine layer winds, wind stress, and wind stress curl along California and Baja California in June 1999. J. Phys. Oceanogr., 34, 1152-1173.

— J. A. Businger, C. E. Dorman, and J. M. Lewis, 2005: Formation, evolution, and dissipation of coastal sea fog. Bound.Layer Meteor., 117, 447-478.

Leipper, D. F., 1994: Fog on the U.S. west coast: A review. Bull. Amer. Meteor. Soc., 75, 229-240.

Lenschow, D. H., and Coauthors, 1988: Dynamics and Chemistry of Marine Stratocumulus (DYCOMS) experiment. Bull. Amer. Meteor. Soc., 69, 1058-1067.

Lewis, J. M., D. Koračin, and K. T. Redmond, 2004: Sea fog research in the United Kingdom and United States: A historical essay including outlook. Bull. Amer. Meteor. Soc., 85, 395408.

Lilly, D. K., 1968: Models of cloud topped mixed layers under a strong inversion. Quart. J. Roy. Meteor. Soc., 94, 292-309.

Luria, M., R. L. Tanner, R. J. Valente, S. T. Bairai, D. Koračin, and A. W. Gertler, 2005: Local and transported pollution over San Diego California. Atmos. Environ., 39, 6765-6776.

Marshall, J. S., and W. M. Palmer, 1948: The distribution of raindrops with size. J. Meteor., 5, 165-166.

Mellor, G. L., and T. Yamada, 1974: A hierarchy of turbulence closure models for planetary boundary layers. J. Atmos. Sci., 31, 1791-1806.

— and _ 1982: Development of turbulence closure model for geophysical fluid problems. Rev. Geophys. Space Phys., 20, 851-875.

Mlawer, E. J., S. J. Taubman, P. D. Brown, M. J. Lacono, and S. A. Clough, 1997: Radiative transfer for inhomogeneous atmosphere: RRTM, a validated correlated k-model for the long wave. J. Geophys. Res., 102 (D14), 16 663-16 682.

Neiburger, M., D. S. Johnson, and C. W. Chien, 1961: Studies of the Structure of the Atmosphere over the Eastern Pacific Ocean in Summer. University of California Press, $94 \mathrm{pp}$.

Nicholls, S., 1984: The dynamics of stratocumulus: Aircraft observations and comparisons with a mixed layer model. Quart. J. Roy. Meteor. Soc., 110, 783-820.

_ 1987: A model of drizzle growth in warm, turbulent, stratiform clouds. Quart. J. Roy. Meteor. Soc., 113, 1141-1170.

Nuss, W. A., and Coauthors, 2000: Coastally trapped wind reversals: Progress toward understanding. Bull. Amer. Meteor. Soc., 81, 719-743.

Reisner, J., R. J. Rasmussen, and R. T. Bruintjes, 1998: Explicit forecasting of supercooled liquid water in winter storms using the MM5 mesoscale model. Quart. J. Roy. Meteor. Soc., 124B, 1071-1107.

Rogers, D. P., and Coauthors, 1998: Highlights of Coastal Waves 1996. Bull. Amer. Meteor. Soc., 79, 1307-1326.

Rogers, R. R., and T. Yau, 1989: A Short Course in Cloud Physics. Pergamon Press, 232 pp.

Schultz, P., 1995: An explicit cloud physics parameterization for operational numerical weather prediction. Mon. Wea. Rev., 123, 3331-3343.

Skamarock, W. C., J. B. Klemp, J. Dudhia, D. O. Gill, D. M. Barker, W. Wang, and J. G. Powers, 2005: A description of the Advanced Research WRF version 2. NCAR Tech Note $468+$ STR, 88 pp

Stage, S. A., and J. A. Businger, 1981: A model for entrainment into a cloud-topped marine boundary layer. Part I: Model description and application to a cold-air outbreak episode. $J$. Atmos. Sci., 38, 2213-2229.

Stauffer, D. R., and N. L. Seaman, 1990: Use of four-dimensional data assimilation in a limited-area mesoscale model. Part I: Experiments with synoptic-scale data. Mon. Wea. Rev., 118, 1250-1277.

Stevens, B., and Coauthors, 2003a: Dynamics and Chemistry of Marine Stratocumulus-DYCOMS-II. Bull. Amer. Meteor. Soc., 84, 580-593.

— istry of Marine Stratocumulus-DYCOMS-II: Flight summaries. Bull. Amer. Meteor. Soc., 84 (5), S12-S25.

_ and Coauthors, 2005: Evaluation of large-eddy simulations via observations of nocturnal marine stratocumulus. Mon. Wea. Rev., 133, 1443-1462. 
Stull, R. B., 1988: An Introduction to Boundary Layer Meteorology. Kluwer Acadamic, 666 pp.

Thompson, G., R. M. Rasmussen, and K. Manning, 2004: Explicit forecasts of winter precipitation using an improved bulk microphysics scheme. Part I: Description and sensitivity analysis. Mon. Wea. Rev., 132, 519-542.

van Zanten, M. C., B. Stevens, G. Vali, and D. H. Lenschow, 2005: Observations of drizzle in nocturnal marine stratocumulus. $J$. Atmos. Sci., 62, 88-106.

Vellore, R., D. Koračin, and M. Wetzel, 2006: A method of improving cloud predictions for real-time forecasting and visualization. Advances in Visual Computing, G. Bebis et al., Eds., Springer, 544-553.

Walko, R. L., W. R. Cotton, M. P. Meyers, and J. Y. Harrington,
1995: New RAMS cloud microphysical parameterization. Part I: The single moment scheme. Atmos. Res., 38, 29-62.

Wang, Q., and B. A. Albrecht, 1994: Observations of cloud-top entrainment in marine stratocumulus. J. Atmos. Sci., 51, 1530-1547.

Wetzel, M. A., G. Vali, W. Thompson, S. Chai, T. Haack, M Szumowski, and R. Kelly, 2001: Evaluation of COAMPS forecasts using satellite retrievals and aircraft measurements. Wea. Forecasting, 16, 588-599.

Wilks, D. S., 1995: Statistical Methods in Atmospheric Sciences. Academic Press, 467 pp.

Willmott, C. J., 1982: Some comments on the evaluation of the model performance. Bull. Amer. Meteor. Soc., 63, 1309-1313.

Young, K. C., 1993: Microphysical Processes in Clouds. Oxford University Press, 427 pp. 